Supporting Information for:

\title{
Synthesis and Solution Self-Assembly Properties of
}

\section{Cyclic Rod-Coil Diblock Copolymers}

Lingfeng Gao, Zhichao Ji, Yiming Zhao, Yuanli Cai, Xiaohong Li and Yingfeng Tu

Table of Contents:

Page(s)

Materials

Experimental Section S2-S6

Instrumentations and Measurements. .S6-S8

Scheme S1-2......

Table S1-3. S10-S12

Supporting Figures

S13-S37

References S38 


\section{Materials}

$N, N, N^{\prime}, N^{\prime}, N^{\prime}$-pentamethyldiethylenetriamine (PMDETA, 99\%) was purchased from Alfa Aesar and toluene (AR, 98.5\%), cyclohexane (AR, 98.5\%), calcium hydride $\left(\mathrm{CaH}_{2}, \mathrm{CP}, 99 \%\right)$, neutral alumina (PH 6.5 7.5, 100 200 mesh) were purchased from Sinopharm Chemical of Shanghai, China. Chloromethyl resin was purchased from Yuanju Biotechnological of Shanghai, China. Triethylamine (98\%) was purchased from TCI (Shanghai) Development Co., Ltd. All other reagents were purchased from Qiangsheng Chemical of Suzhou, China and used as received unless otherwise stated. Prior to use, $p$-xylene (AR, 98.5\%) and chlorobenzene (AR, 98.5\%) were washed three times with concentrated sulfuric acid, twice with 5\% aqueous solution of sodium bicarbonate and twice with water, dried with anhydrous magnesium sulfate, and distilled over $\mathrm{CaH}_{2}$. Styrene was washed three times with $5 \%$ aqueous solution of sodium hydroxide and twice with water, dried with anhydrous magnesium sulfate, and then distilled over $\mathrm{CaH}_{2}$ under vacuum. Copper (I) bromide $(\mathrm{CuBr}, \mathrm{CP}, 99 \%)$ was purified by stirring with glacial acetic acid (AR, 98\%), followed by filtering and washing twice with ethanol (AR, 98\%) and twice with acetone (AR, 98\%). Chloromethyl resin was reacted with sodium azide for $24 \mathrm{~h}$ in DMF solution, washed with a large amount of DMF and water. The obtained azide resin was dried in a vacuum oven for $24 \mathrm{~h}$ and stored in an argon atmosphere at $5^{\circ} \mathrm{C}$.

\section{Experimental Section}

\section{Synthesis of but-3-yn-1-yl 2-bromopropanoate initiator}

But-3-yn-1-yl 2-bromopropanoate was synthesized by drop-wise addition of 2-bromopropiomyl bromide (14.0 g, $65.0 \mathrm{mmol})$ to 3-butyn-1-ol $(4.55 \mathrm{~g}, 65.0 \mathrm{mmol})$ and triethylamine $(6.40 \mathrm{~g}, 65.0$ mmol) solution in THF $(100 \mathrm{~mL})$ at $0{ }^{\circ} \mathrm{C}$. After addition, the reaction mixture was stirred 
overnight at room temperature. The reaction mixture was diluted with ethyl acetate and washed with excess water, and the organic phase was dried with anhydrous $\mathrm{MgSO}_{4}$. After the removal of solvent under reduced pressure, the colorless product was obtained by distillation under reduced pressure. ${ }^{1} \mathrm{H}$ NMR (600 MHz, $\left.\mathrm{CDCl}_{3}\right), \delta(\mathrm{TMS}, \mathrm{ppm}): 4.39$ (q, $\left.1 \mathrm{H}, \mathrm{CHBrCH}_{3}\right) ; 4.28(\mathrm{t}, 2 \mathrm{H}$, $\left.\mathrm{COOCH}_{2} \mathrm{CH}_{2}\right) ; 2.58\left(\mathrm{~m}, 2 \mathrm{H}, \mathrm{COOCH}_{2} \mathrm{CH}_{2}\right) ; 2.01\left(\mathrm{t}, 1 \mathrm{H}, \mathrm{COOCH}_{2} \mathrm{CH}_{2} \mathrm{C} \equiv \mathrm{CH}\right) ; 1.84(\mathrm{~d}, 3 \mathrm{H}$, $\left.\mathrm{CHBrCH}_{3}\right)$.

\section{Sythesis of polystyrene macroinitiator and linear $\alpha$-alkynyl- $\omega$-bromo poly(styrene-block- (2,5-bis[4-methoxyphenyl]oxycarbonyl)styrene) (l-PS-b-PMPCS-Br)}

A typically atom transfer radical polymerization (ATRP) procedure was given below for the polymerization of styrene using but-3-yn-1-yl 2-bromopropanoate as initiator (Scheme S1). Styrene $(20 \mathrm{~mL}, 0.17 \mathrm{~mol})$, initiator $(65 \mu \mathrm{L}, 0.35 \mathrm{mmol})$, and $p$-xylene $(20 \mathrm{~mL})$ were added into a $100 \mathrm{~mL}$ Schlenk flask, after two cycles of freeze-pump-thaw, PMDETA (230 $\mu \mathrm{L}, 1.05 \mathrm{mmol})$ and $\mathrm{CuBr}$ (40 mg, $0.35 \mathrm{mmol})$ were added. After the third freeze-pump-thaw cycle, the reaction mixture was warmed to room temperature, placing in an oil bath thermostated at $85{ }^{\circ} \mathrm{C}$ and allowed to stir for 10 hours. The mixture was passed through a neutral alumina column to remove the catalyst. After removing the solvent by rotary evaporation, the residues were precipitated into an excess amount of methanol. The final product was collected by filtration, dried at $40{ }^{\circ} \mathrm{C}$ under vacuum overnight and characterized by SEC $\left(4.16 \mathrm{~g}\right.$, yield: $23 \%, M_{\mathrm{n}, \mathrm{SEC}}=$ $\left.9.42 \mathrm{~kg} / \mathrm{mol}, M_{\mathrm{w}} / M_{\mathrm{n}}=1.03\right)$. A similar procedure was conducted for the synthesis of $l$-PS- $b$ PMPCS-Br using polystyrene as macroinitiator, (2,5-bis[4-methoxyphenyl]oxycarbonyl)styrene (MPCS) as monomer and chlorobenzene as solvent instead of $p$-xylene for better solubility. MPCS was synthesized according to the literature ${ }^{1}$. After removing the catalyst, the copolymer 
was extracted with cyclohexane to remove the unreacted macroinitiator and dried in vacuum (yield: $75 \%, M_{\mathrm{n}, \mathrm{SEC}}=27.6 \mathrm{~kg} / \mathrm{mol}, M_{\mathrm{w}} / M_{\mathrm{n}}=1.13$ ).

Synthesis of linear $\quad \alpha$-alkynyl- $\omega$-azido poly(styrene-block-(2,5-bis[4methoxyphenyl]oxycarbonyl)styrene) (l-PS-b-PMPCS-N 3 )

A $50 \mathrm{~mL}$ round bottom flask was charged with $l$-PS- $b$-PMPCS-Br (1.5 g, $0.054 \mathrm{mmol})$, DMF (20 $\mathrm{mL})$, and $\mathrm{NaN}_{3}(0.11 \mathrm{~g}, 1.7 \mathrm{mmol})$. The reaction mixture was allowed to stir overnight at room temperature before precipitating into methanol. (1.35 g, yield: $90 \%, M_{\mathrm{n}, \mathrm{SEC}}=27.6 \mathrm{~kg} / \mathrm{mol}$, $\left.M_{\mathrm{w}} / M_{\mathrm{n}}=1.13\right)$.

Synthesis of cyclic poly(styrene-block-(2,5-bis[4-methoxyphenyl]oxycarbonyl)styrene) (cPS- $b$-PMPCS) via high dilute condition method

Into a $1000 \mathrm{~mL}$ four-necked round-bottom flask was added $300 \mathrm{~mL}$ toluene and deoxygenated by bubbling with argon for $2 \mathrm{~h}$. After that, $\mathrm{CuBr}(9.5 \mathrm{mg}, 0.066 \mathrm{mmol})$ and PMDETA (14 $\mu \mathrm{L}, 0.066$ mmol) were added into the flask under the protection of argon. $400 \mathrm{~mL}$ toluene of $l$-PS- $b$ PMPCS-N $\mathrm{N}_{3}$ was added slowly into the $1000 \mathrm{~mL}$ flask at $60^{\circ} \mathrm{C}$. After the addition of polymer solution, the reaction was further stirred for $12 \mathrm{~h}$. The finial concentrations were 0.14 and 0.28 $\mathrm{g} / \mathrm{L}$ for two different experiments. After removing the toluene by rotary evaporation, the copper salts were removed by passing through a neutral alumina column. After precipitation into methanol, the cyclic polymer was collected by filtration and drying under vacuum.

\section{Preparation of linear and cyclic diblock copolymer micelles}

$l$-PS- $b$-PMPCS-N $3(20 \mathrm{mg})$ was dissolved in toluene $(10 \mathrm{~mL})$ at room temperature and same volume amount of cyclohexane was added to prepare a $1: 1\left(\mathrm{~V}_{\text {toluene }}: \mathrm{V}_{\text {cyclohexane }}\right)$ system. The 
mixture was then kept for $12 \mathrm{~h}$ to reach equilibrium. This solution was then diluted to obtain a series of concentrations, $0.5 \mathrm{~g} / \mathrm{L}, 0.4 \mathrm{~g} / \mathrm{L}, 0.25 \mathrm{~g} / \mathrm{L}, 0.2 \mathrm{~g} / \mathrm{L}, 0.1 \mathrm{~g} / \mathrm{L}, 0.05 \mathrm{~g} / \mathrm{L}, 0.025 \mathrm{~g} / \mathrm{L}, 0.01 \mathrm{~g} / \mathrm{L}$, $0.005 \mathrm{~g} / \mathrm{L}$ and $0.0025 \mathrm{~g} / \mathrm{L}$, for other measurements. Similar procedure was conducted for different solvent ratio systems of linear and cyclic diblock copolymers.

\section{Synthesis of $c$-PS- $b$-PMPCS under micellar condition}

After deoxygenated by argon, certain amounts of $\mathrm{CuBr}$ and PMDETA were added into the prepared linear precursor micelle solution to start the cyclization. The reaction was stopped after $12 \mathrm{~h}$ by removing copper catalysts via passing through a neutral alumina column. The solvents were removed by rotary evaporation, and the residues were dried in a vacuum oven for $24 \mathrm{~h}$ at $40{ }^{\circ} \mathrm{C}$. Cyclizations under micellar conditions were conducted in various toluene/cyclohexane systems $(2: 3,1: 1$ and $3: 2)$ at different temperatures $\left(40,50,60^{\circ} \mathrm{C}\right)$, with various $l$-PS- $b$-PMPCS$\mathrm{N}_{3}$ concentrations $(2.0,5.0,10 \mathrm{~g} / \mathrm{L})$.

\section{Purification of $c$-PS- $b$-PMPCS by azide resin}

As the linear contaminations in the cyclic product have alkyne end-groups, they can be removed by azide resin treatment. ${ }^{2}$ In a typical process, crude cyclic product $(\sim 20 \mathrm{mg})$ and azide resin $(20$ $\mathrm{mg}$ ) were dispersed in $5 \mathrm{~mL}$ THF and degassed with argon for $1 \mathrm{~h}$. After that, $\mathrm{CuBr}(20 \mathrm{mg})$ and PMDETA $(30 \mu \mathrm{L})$ were added into the flask under the protection of argon. The mixture was

further stirred for $12 \mathrm{~h}$. The azide resin and copper salts were removed by passing through a neutral alumina column using THF as eluent. THF was removed by rotary evaporation, and the residues were dried in a vacuum oven for $24 \mathrm{~h}$ at $40^{\circ} \mathrm{C}$.

\section{Refractive index increment measurement of polymer}


The specific refractive index increment $(\mathrm{d} n / \mathrm{d} C)$ of diblock copolymers in selective solvent can't be directly measured due to their strong light scattering at high concentrations. As the specific refractive index increment $(\mathrm{d} n / \mathrm{d} C)$ of PS and PMPCS are nearly identical, ${ }^{3}$ this value of diblock copolymer in mixed solvent can be considered the same as that of PS. A series of PS with different concentrations $(10.0 \mathrm{~g} / \mathrm{L}, 8.0 \mathrm{~g} / \mathrm{L}, 6.0 \mathrm{~g} / \mathrm{L}, 4.0 \mathrm{~g} / \mathrm{L}$ and $2.0 \mathrm{~g} / \mathrm{L})$ in mixture solvents $(30 \%, 40 \%, 50 \%$ toluene fraction) were prepared by diluting their relative high concentration solution $(10.0 \mathrm{~g} / \mathrm{L})$ and the specific refractive index increment was determined by a novel and precise differential refractometer (Brookhaven BI-DNDC $620 \mathrm{~nm}$ ). ${ }^{4}$ The measured $\mathrm{d} n / \mathrm{d} C$ of polystyrene is $0.140 \mathrm{~mL} / \mathrm{g}$ in $1: 1 \quad\left(\mathrm{~V}_{\text {toluene }}: \mathrm{V}_{\text {cyclohexane }}\right)$ system, $0.144 \mathrm{~mL} / \mathrm{g}$ for $2: 3$ ( $\left.\mathrm{V}_{\text {toluene }}: \mathrm{V}_{\text {cyclohexane }}\right)$ system and $0.148 \mathrm{~mL} / \mathrm{g}$ for $3: 7\left(\mathrm{~V}_{\text {toluene }}: \mathrm{V}_{\text {cyclohexane }}\right)$ system, respectively.

\section{Instrumentations and Measurements}

Size exclusion chromatography (SEC) was performed on a PL-GPC 120 integrated system fitted with a refractive index detector. Separations were achieved using a set of columns $(2 \times$ PLGel MIXED-B $+1 \times$ PLGel MIXED-D), calibrated with a series of narrow distribution polystyrene standards with a molecular weight range from 580 to 300000 Dalton. All samples (2 mg/mL) were passed through $0.45 \mu \mathrm{m}$ PTFE filter prior to injection, and DMF was used as mobile phase at a flow rate of $1.0 \mathrm{~mL} / \mathrm{min}$. Monocyclization yield was calculated by Origin's Fit Multi-Peaks software analysis from the corresponding SEC curve.

${ }^{1} \mathrm{H}$ nuclear magnetic resonance (NMR) spectra were recorded on An INOVA $400 \mathrm{MHz}$ nuclear magnetic resonance instrument at $25{ }^{\circ} \mathrm{C}$, using deuterated dichloromethane $\left(\mathrm{CD}_{2} \mathrm{Cl}_{2}\right)$ as solvent and tetramethylsilane (TMS) as internal reference. DOSY experiments were carried out on an 
Agilent $600 \mathrm{MHz}$ nuclear magnetic resonance instrument at $25^{\circ} \mathrm{C}$ using $\mathrm{CD}_{2} \mathrm{Cl}_{2}$ as solvent with copolymer concentration at $1.0 \mathrm{mg} / \mathrm{mL}$.

Fourier transform infrared (FTIR) spectra were collected on Nicolet 6700 FT-IR instrument. Samples were dispersed in potassium bromide uniformly and compressed into pellets. The spectra were recorded with a resolution of $4 \mathrm{~cm}^{-1}$ co-adding 32 scans with the range from 400 $\mathrm{cm}^{-1}$ to $4000 \mathrm{~cm}^{-1}$.

Transmission electron microscopy (TEM) experiments were conducted on an FEI Tecnai F20 transmission electron microscope at an acceleration voltage of $120 \mathrm{kV}$.

Laser light scattering (LLS) was conducted on Brookhaven BI-200SM setup fitted with $35 \mathrm{~mW}$ He-Ne laser $\left(\lambda_{0}=632.8 \mathrm{~nm}\right), \mathrm{BI}-200 \mathrm{SM}$ goniometer and BI-9000AT digital correlator. All solutions were filtered by a $0.45 \mu \mathrm{m}$ Millipore Millex-PTFE filter before analysis. In dynamic LLS, The intensity-average hydrodynamic radius $\left(R_{\mathrm{h}}\right)$ and the dispersity $\left(\mu_{2} / \Gamma^{2}\right)$ of particles were determined by cumulant analysis while the hydrodynamic radius distribution $\left(\mathrm{f}\left(R_{\mathrm{h}}\right)\right)$ was obtained from CONTIN routines. All data were averaged over three runs and each was collected for $30 \mathrm{~min}$. In static LLS, the excess absolute time-average scattered light intensity, known as the excess Rayleigh ratio $R_{\mathrm{vv}}(q)$, of a dilute polymer solution at concentration $C$ is related to the weight-average molar mass $M_{\mathrm{w}}$, the root-mean square $z$-average radius of gyration $R_{\mathrm{g}}$, and the scattering vector $q$ by the Debye equation, as

$$
\frac{K C}{R_{v v}(q)} \approx \frac{1}{M_{w}}\left(1+\frac{1}{3}<R_{g}{ }^{2}>q^{2}\right)+2 A_{2} C
$$

where $K=4 \pi^{2} n^{2}(\mathrm{~d} n / \mathrm{d} C)^{2} /\left(N_{\mathrm{A}} \lambda_{0}{ }^{4}\right)$ and $q=\left(4 \pi n / \lambda_{0}\right) \sin (\theta / 2)$ with $N_{\mathrm{A}}, \mathrm{d} n / \mathrm{d} C, n$, and $\lambda_{0}$ being the Avogadro constant, the specific refractive index increment, the solvent refractive index, and the 
wavelength of the light in a vacuum, and $A_{2}$ is the second virial coefficient, respectively. The extrapolation of $R_{\mathrm{vv}}(q)$ to $q \rightarrow 0$ and $C \rightarrow 0$ leads to $M_{\mathrm{w}}$. The plots of reduced reciprocal scattered intensity, $\left[K C / R_{\mathrm{vv}}(q)\right]_{c \rightarrow 0}$, vs $q^{2}$ and $\left[K C / R_{\mathrm{vv}}(q)\right]_{q \rightarrow 0}$ vs $C$ respectively lead to $<R_{\mathrm{g}}{ }^{2}>$ and $A_{2}$. For finite concentrations, Zimm plot of $K C / R_{\mathrm{vv}}(q)$ is usually used, which incorporates the extrapolation of $C \rightarrow 0$ and $q \rightarrow 0$ in a single grid. To determine the correct weight-average molar mass of the self-assembled particle, CAC should be taken into consideration for the correction as following 3

$$
\frac{K\left(C-C_{\mathrm{CAC}}\right)}{R_{v v}(q)-R_{v v}(q)_{\mathrm{CAC}}} \approx \frac{1}{M_{w}}\left(1+\frac{1}{3}<R_{g}{ }^{2}>q^{2}\right)+2 A_{2}\left(C-C_{\mathrm{CAC}}\right)
$$

where $R_{\mathrm{vv}}(q)$ and $R_{\mathrm{vv}}(q)_{\mathrm{CAC}}$ are the Rayleigh ratios of the solution and the solution at the CAC, respectively. The combination of dynamic and static LLS studies can reveal the $\rho$ parameter of the self-assembled core-shell micelle as described: ${ }^{6}$

$$
\rho=\frac{R_{\mathrm{g}}}{R_{\mathrm{h}}}=\left\{\frac{3\left[A x^{2}-(1+A) x^{5}+1\right]}{5(1+A)\left(1-x^{3}\right)}\right\}^{\frac{1}{2}}
$$

where $R_{\mathrm{g}}$ and $R_{\mathrm{h}}$ is the $z$-average radius of gyration and hydrodynamic radius of the micelles, $A$ is the mass ratio of the core to shell (a constant for a given diblock copolymer), $x=R_{\mathrm{d}} / R_{\mathrm{h}}$ while $R_{\mathrm{c}}$ is the core radius of micelle. Therefore, the radius of core and corona of the micelle can be further calculated. 
Scheme S1. Synthetic route of but-3-yn-1-yl 2-bromopropanoate.

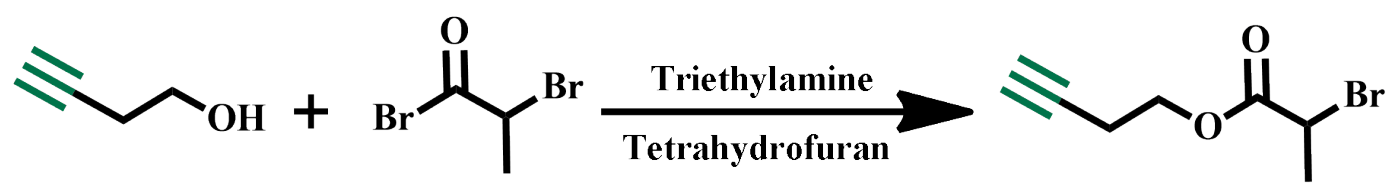

Scheme S2. Synthetic route of linear and cyclic PS- $b$-PMPCS rod-coil diblock copolymers.<smiles>C#CCCOC(=O)C(C)Br</smiles>

1
$+$

2<smiles>C#CCCOC(=O)C(C)CC(Br)c1ccccc1</smiles>

4

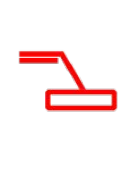

5

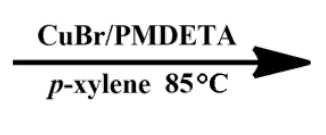<smiles>C#CCCOC(=O)C(C)CC(Br)c1ccccc1</smiles>

3<smiles>C#CCCOC(=O)C(C)CC(C)C(C)CC(C)C(C)Br</smiles>

6

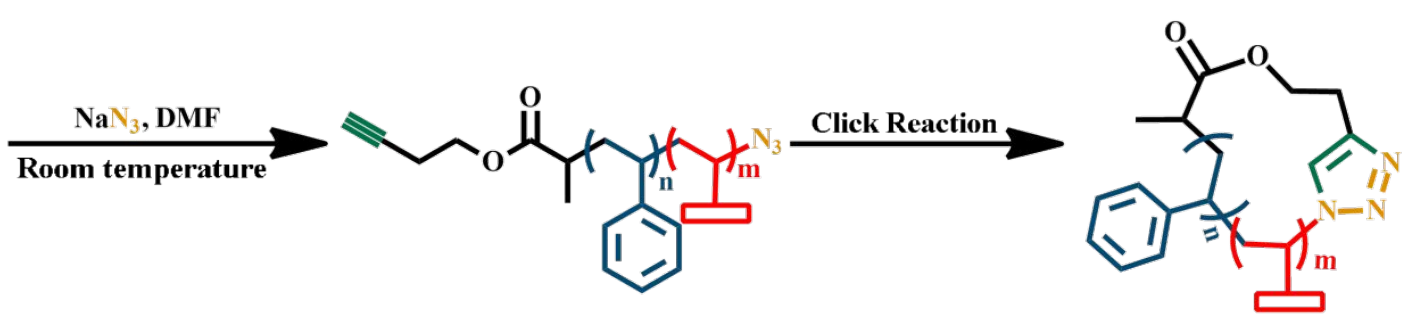<smiles>C=Cc1cc(C(=O)Oc2ccc(OC)cc2)ccc1C(=O)Oc1ccc(OC)cc1</smiles> 
Table S1. Molecular weight and PDI of PS macroinitiator and linear diblock copolymer.

\begin{tabular}{cccc}
\hline Sample & $M_{\mathrm{n}}{ }^{[\mathrm{a}]}(\mathrm{g} / \mathrm{mol})$ & $\begin{array}{c}M_{\mathrm{n}}{ }^{[\mathrm{b}]} \\
(\mathrm{g} / \mathrm{mol})\end{array}$ & PDI [a] \\
\hline PS & 9420 & 9380 & 1.03 \\
$l$-PS- $b$-PMPCS-Br & 27600 & 30200 & 1.13 \\
$l$-PS- $b$-PMPCS-N 3 & 27600 & 30200 & 1.13 \\
\hline
\end{tabular}

[a]Date obtained from SEC. ${ }^{[b]}$ Data acquired from NMR. 
Table S2. CAC values of $l-\mathrm{PS}_{90}-b$-PMPCS ${ }_{52}-\mathrm{N}_{3}$ in different toluene/cyclohexane mixture solvent systems at different temperatures.

\begin{tabular}{ccccc}
\hline $\mathrm{V}_{\text {toluene }}: \mathrm{V}_{\text {cyclohexane }}$ & $25^{\circ} \mathrm{C}(\mathrm{g} / \mathrm{L})$ & $40{ }^{\circ} \mathrm{C}(\mathrm{g} / \mathrm{L})$ & $50^{\circ} \mathrm{C}(\mathrm{g} / \mathrm{L})$ & $60{ }^{\circ} \mathrm{C}(\mathrm{g} / \mathrm{L})$ \\
\hline $7: 3$ & 0.3 & $>0.5$ & $>0.5$ & $>0.5$ \\
$3: 2$ & 0.062 & 0.13 & 0.15 & 0.16 \\
$1: 1$ & 0.0073 & 0.015 & 0.025 & 0.065 \\
$2: 3$ & 0.0042 & 0.0061 & 0.0072 & 0.0086 \\
$3: 7$ & $<0.0025$ & $<0.0025$ & $<0.0025$ & $<0.0025$ \\
\hline
\end{tabular}


Table S3. Yield of monocyclic diblock copolymer obtained under various conditions.

\begin{tabular}{|c|c|c|c|c|c|c|c|c|}
\hline $\begin{array}{c}40 \% \\
\text { Toluene }\end{array}$ & $\begin{array}{c}C \\
(\mathrm{~g} / \mathrm{L})^{[\mathrm{b}]}\end{array}$ & $\begin{array}{l}\text { Yield } \\
(\%)^{[\mathrm{c}]}\end{array}$ & $\begin{array}{c}50 \% \\
\text { Toluene }\end{array}$ & $\begin{array}{c}C \\
(\mathrm{~g} / \mathrm{L})^{[\mathrm{b}]}\end{array}$ & $\begin{array}{l}\text { Yield } \\
(\%)^{[c]}\end{array}$ & $\begin{array}{c}60 \% \\
\text { Toluene }\end{array}$ & $\begin{array}{c}C \\
(\mathrm{~g} / \mathrm{L})^{[\mathrm{b}]}\end{array}$ & $\begin{array}{l}\text { Yield } \\
(\%)^{[\mathrm{c}]}\end{array}$ \\
\hline \multirow{3}{*}{$\begin{array}{c}40^{\circ} \mathrm{C} \\
(0.0061 \\
g / L)^{[a]}\end{array}$} & 2.0 & 86 & & 2.0 & 89 & \multirow{3}{*}{$\begin{array}{c}40^{\circ} \mathrm{C} \\
(0.13 \mathrm{~g} / \mathrm{L})^{[\mathrm{a}]}\end{array}$} & \multirow{3}{*}{2.0} & \multirow{3}{*}{66} \\
\hline & 5.0 & 83 & $\begin{array}{l}40^{\circ} \mathrm{C} \\
(0.015 \\
g / L)^{[a]}\end{array}$ & 5.0 & 84 & & & \\
\hline & 10.0 & 80 & & 10.0 & 79 & & & \\
\hline \multirow{3}{*}{$\begin{array}{c}50^{\circ} \mathrm{C} \\
(0.0072 \\
\mathrm{g} / \mathrm{L})^{[\mathrm{a}]}\end{array}$} & 2.0 & 90 & \multirow{3}{*}{$\begin{array}{l}50^{\circ} \mathrm{C} \\
(0.025 \\
g / L)^{[a]}\end{array}$} & 2.0 & 89 & & \multirow{3}{*}{2.0} & \multirow{3}{*}{57} \\
\hline & 5.0 & 84 & & 5.0 & 75 & $\begin{array}{c}50^{\circ} \mathrm{C} \\
(0.15 \mathrm{~g} / \mathrm{L})^{[\mathrm{a}]}\end{array}$ & & \\
\hline & 10.0 & 82 & & 10.0 & 70 & & & \\
\hline \multirow{4}{*}{$\begin{array}{c}60^{\circ} \mathrm{C} \\
(0.0086 \\
g / L)^{[a]}\end{array}$} & 2.0 & 92 & \multirow{4}{*}{$\begin{array}{l}60^{\circ} \mathrm{C} \\
(0.065 \\
g / L)^{[a]}\end{array}$} & 2.0 & 87 & & & \\
\hline & & & & & & & & \\
\hline & 5.0 & 89 & & 5.0 & 72 & & & \\
\hline & 10.0 & 85 & & 10.0 & 63 & & & \\
\hline
\end{tabular}

[a] CAC value of $l$-PS ${ }_{90}-b-\mathrm{PMPCS}_{52}-\mathrm{N}_{3}$ precursor obtained from SLLS.

${ }^{[b]}$ Reaction concentration of $l-\mathrm{PS}_{90}-b-\mathrm{PMPCS}_{52}-\mathrm{N}_{3}$ during cyclization.

[c] Date calculated by Origin's Fit Multi-Peaks software analysis. 


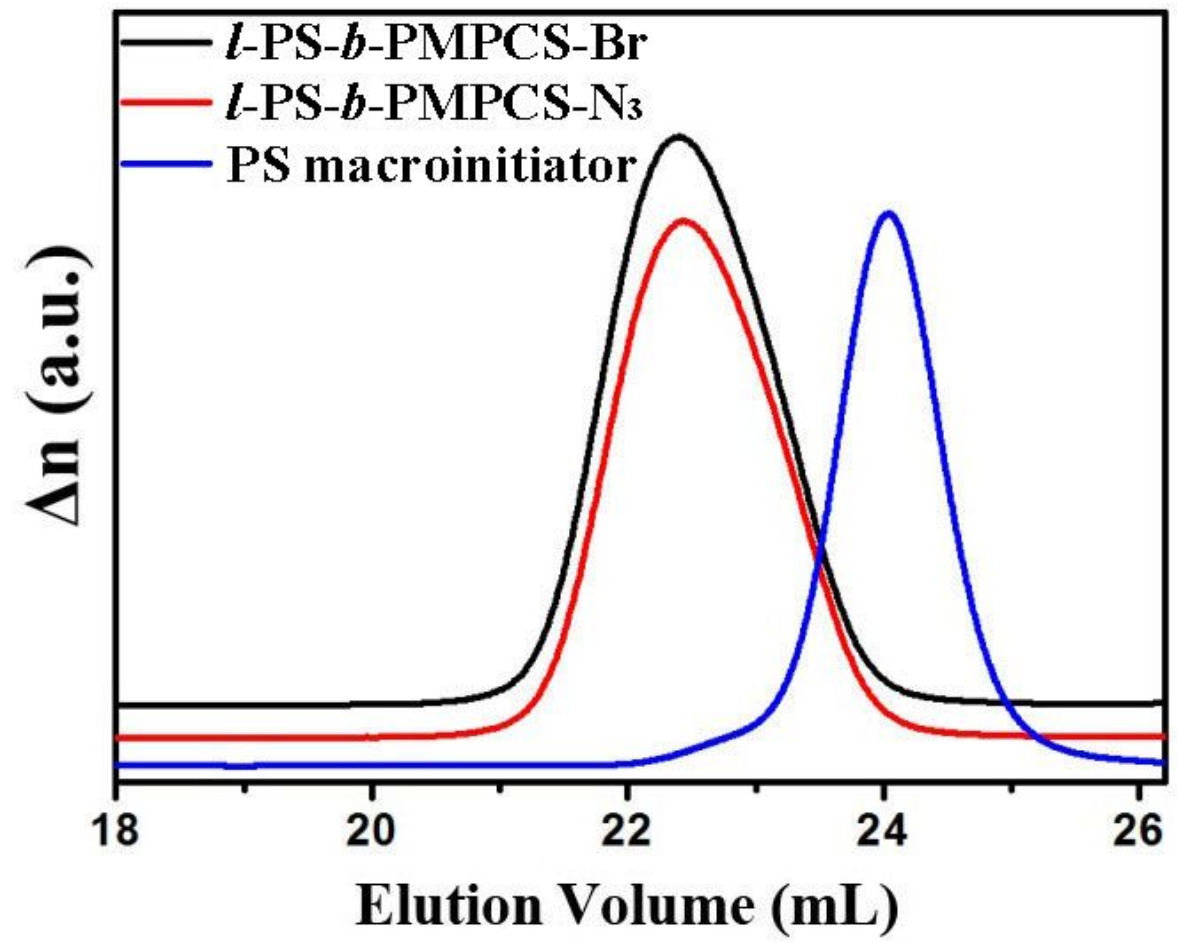

Figure S1. SEC curves of polystyrene macroinitiator, $l-\mathrm{PS}_{90}-b-\mathrm{PMPCS}_{52}-\mathrm{Br}$ and $l-\mathrm{PS}_{90^{-}} b-$ PMPCS $_{52}-\mathrm{N}_{3}$. Eluent: DMF. 


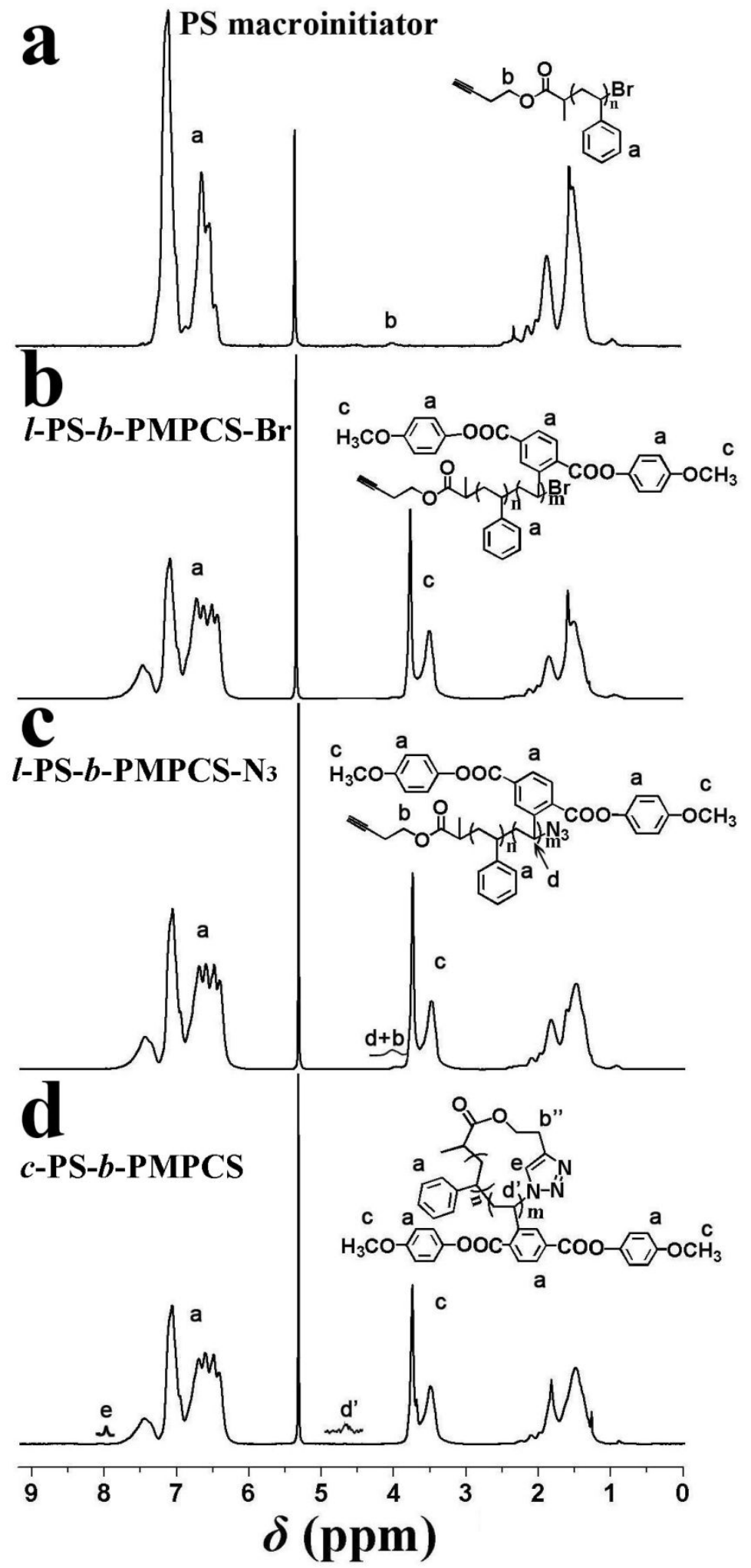

Figure S2. ${ }^{1} \mathrm{H}$ NMR spectra of polystyrene (PS) macroinitiator (a), $l-\mathrm{PS}_{90}-b-\mathrm{PMPCS}{ }_{52}-\mathrm{Br}(\mathrm{b}), l$ $\mathrm{PS}_{90}-b-\mathrm{PMPCS}_{52}-\mathrm{N}_{3}(\mathrm{c})$ and $c-\mathrm{PS}_{90}-b-\mathrm{PMPCS}_{52}(\mathrm{~d})$. 


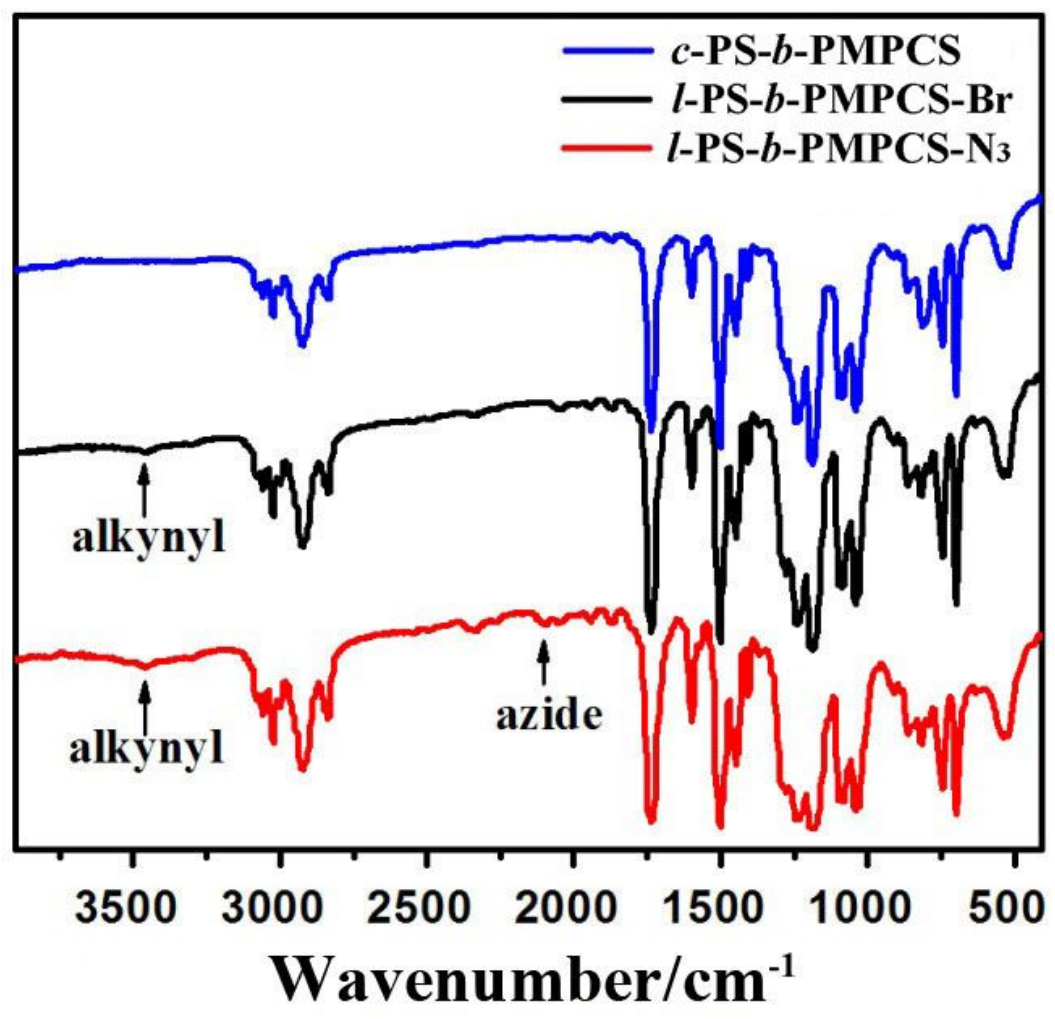

Figure S3. FTIR spectra of $l$-PS ${ }_{90}-b-\mathrm{PMPCS}_{52}-\mathrm{Br}, l-\mathrm{PS}_{90}-b-\mathrm{PMPCS}_{52}-\mathrm{N}_{3}$ and $c-\mathrm{PS}_{90}-b-\mathrm{PMPCS}_{52}$. 


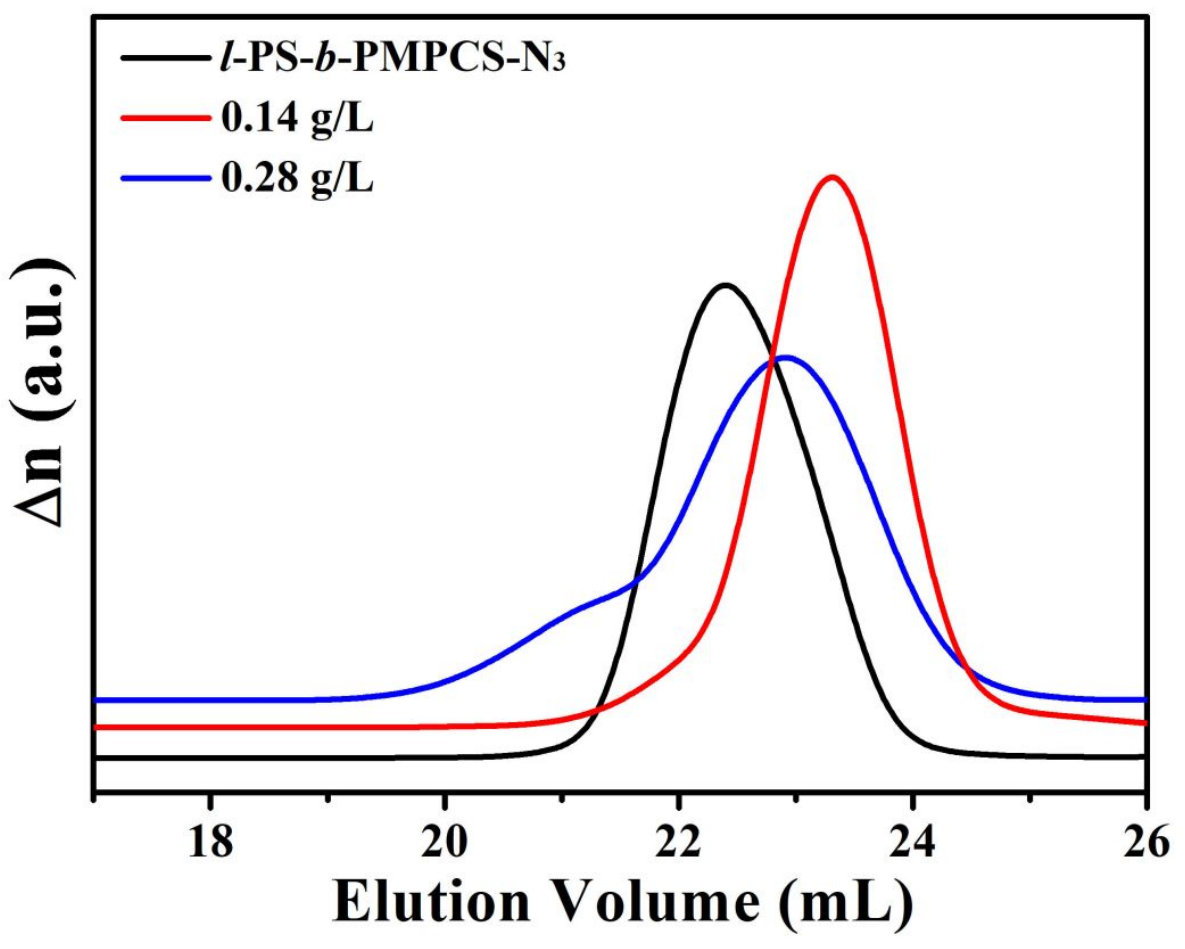

Figure S4. SEC curves of $l-\mathrm{PS}_{90}-b-\mathrm{PMPCS}_{52}-\mathrm{N}_{3}$ precursor and the corresponding cyclization products synthesized at traditional low concentrations of 0.14 and $0.28 \mathrm{~g} / \mathrm{L}$. Eluent: DMF. 


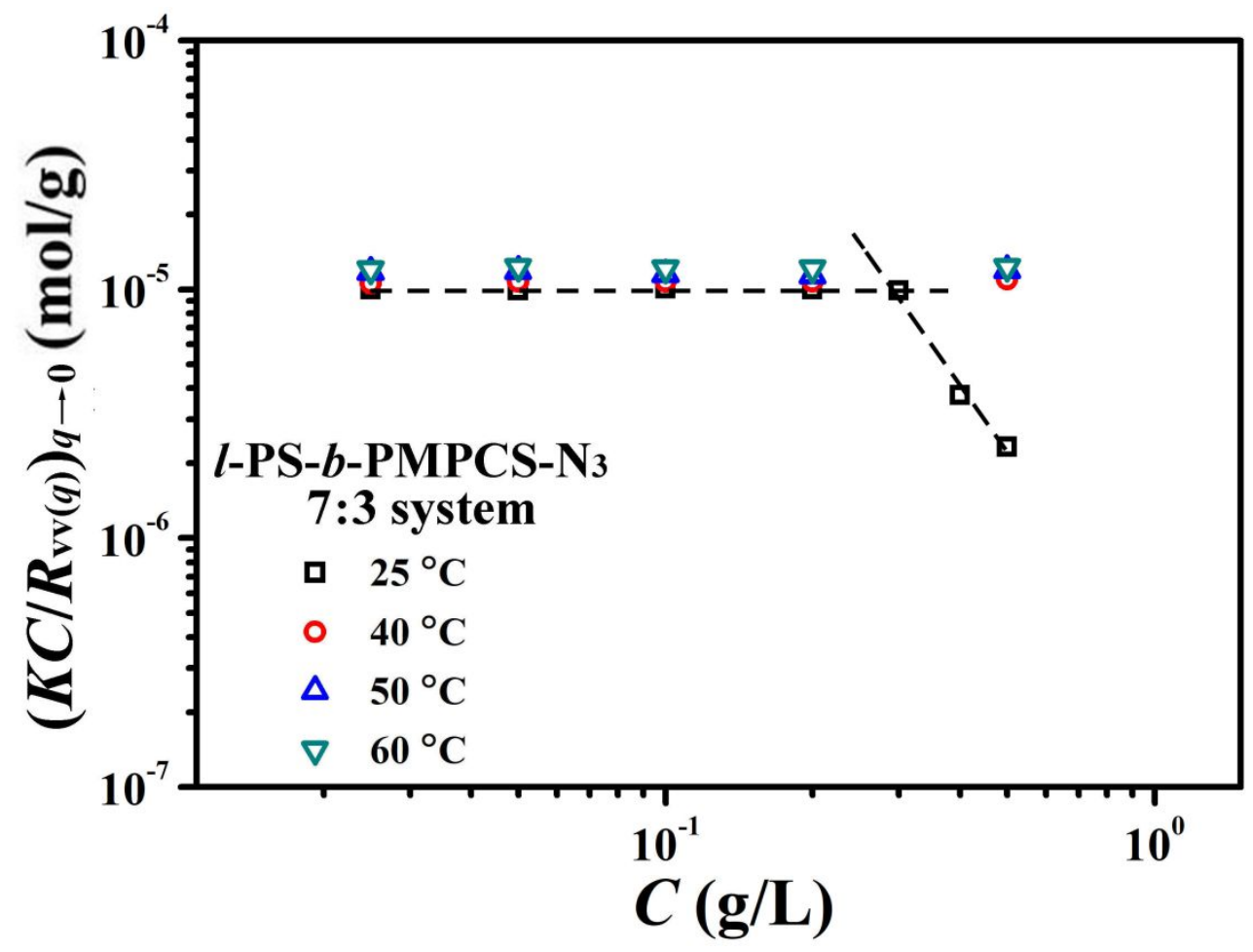

Figure S5. Concentration dependence of the reduced reciprocal scattered intensity $\left(K C / R_{\operatorname{vv}(q)}\right)_{q \rightarrow 0}$ of $l$-PS $90^{-} b-\mathrm{PMPCS}_{52}-\mathrm{N}_{3}$ in $7: 3\left(\mathrm{~V}_{\text {toluene }}: \mathrm{V}_{\text {cyclohexane }}\right)$ system at different temperatures $\left(25^{\circ} \mathrm{C}, 40\right.$ $\left.{ }^{\circ} \mathrm{C}, 50{ }^{\circ} \mathrm{C}, 60^{\circ} \mathrm{C}\right)$. 


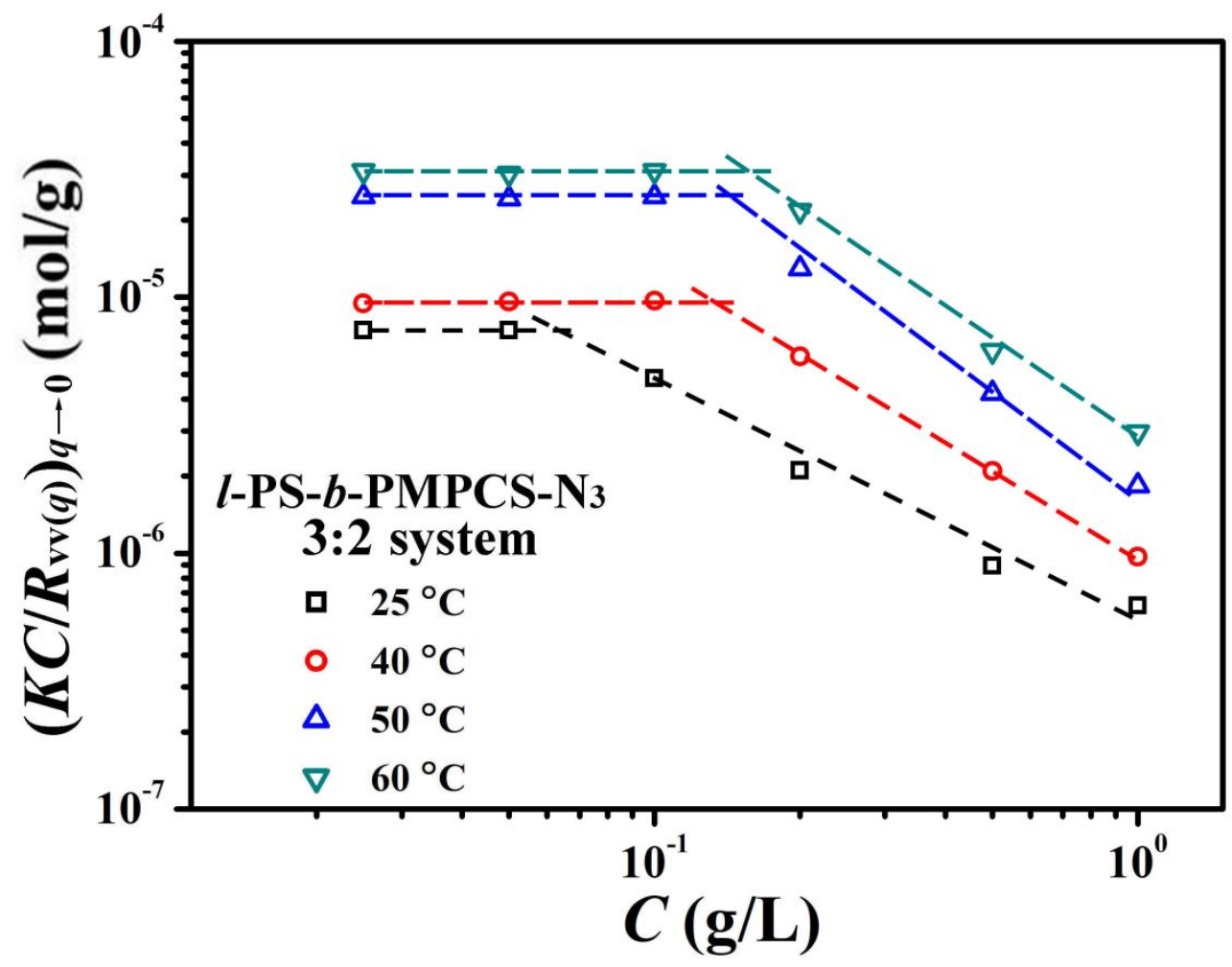

Figure S6. Concentration dependence of the reduced reciprocal scattered intensity $\left(K C / R_{\mathrm{vv}(q)}\right)_{q \rightarrow 0}$ of $l$-PS $90^{-} b$-PMPCS $5_{52}-\mathrm{N}_{3}$ in $3: 2\left(\mathrm{~V}_{\text {toluene }}: \mathrm{V}_{\text {cyclohexane }}\right)$ system at different temperatures $\left(25^{\circ} \mathrm{C}, 40\right.$ $\left.{ }^{\circ} \mathrm{C}, 50{ }^{\circ} \mathrm{C}, 60^{\circ} \mathrm{C}\right)$. 


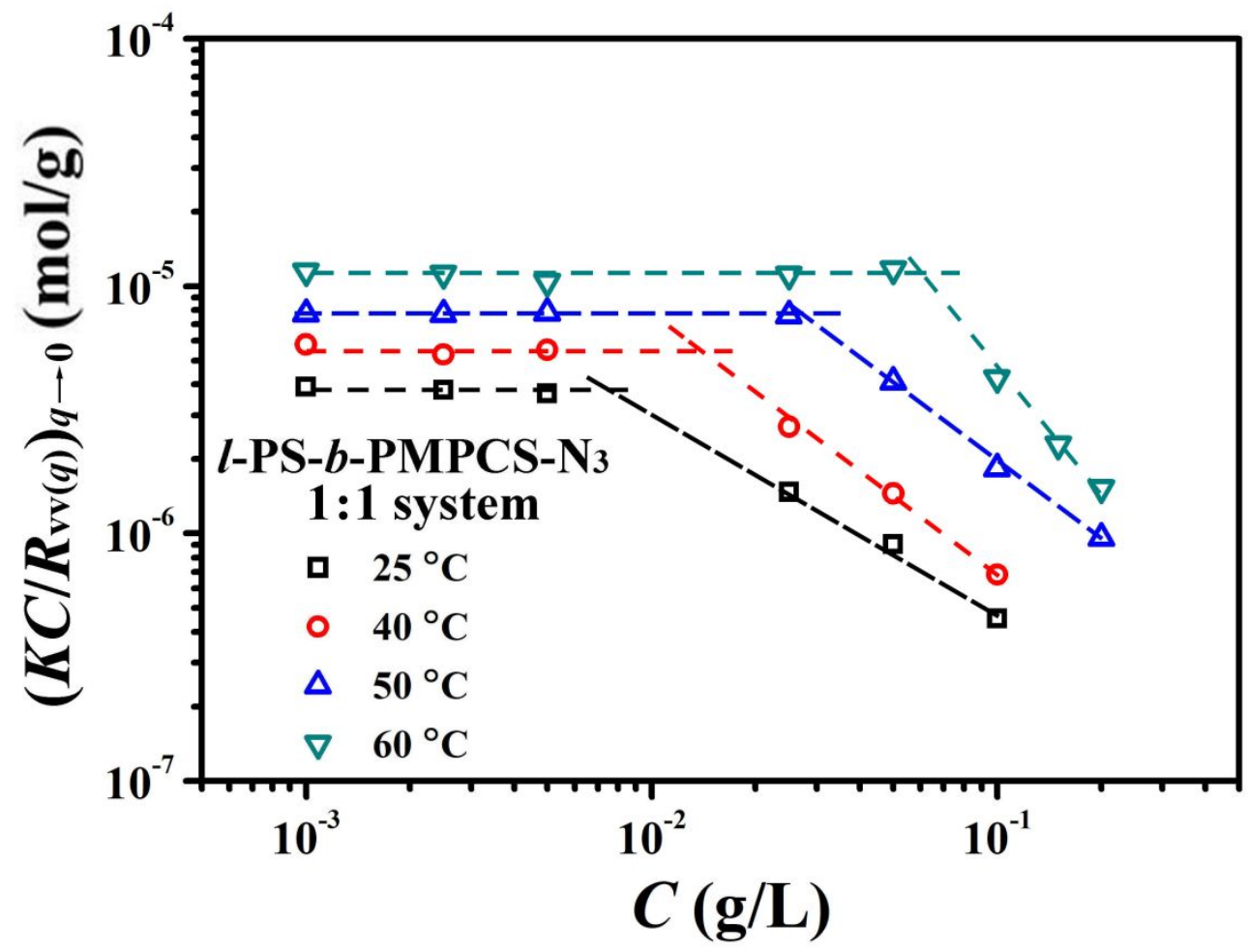

Figure S7. Concentration dependence of the reduced reciprocal scattered intensity $\left(K C / R_{\mathrm{vv}(q)}\right)_{q \rightarrow 0}$ of $l$-PS $90^{-} b$-PMPCS $5_{52}-\mathrm{N}_{3}$ in $1: 1\left(\mathrm{~V}_{\text {toluene }}: \mathrm{V}_{\text {cyclohexane }}\right)$ system at different temperatures $\left(25^{\circ} \mathrm{C}, 40\right.$ $\left.{ }^{\circ} \mathrm{C}, 50{ }^{\circ} \mathrm{C}, 60{ }^{\circ} \mathrm{C}\right)$. 


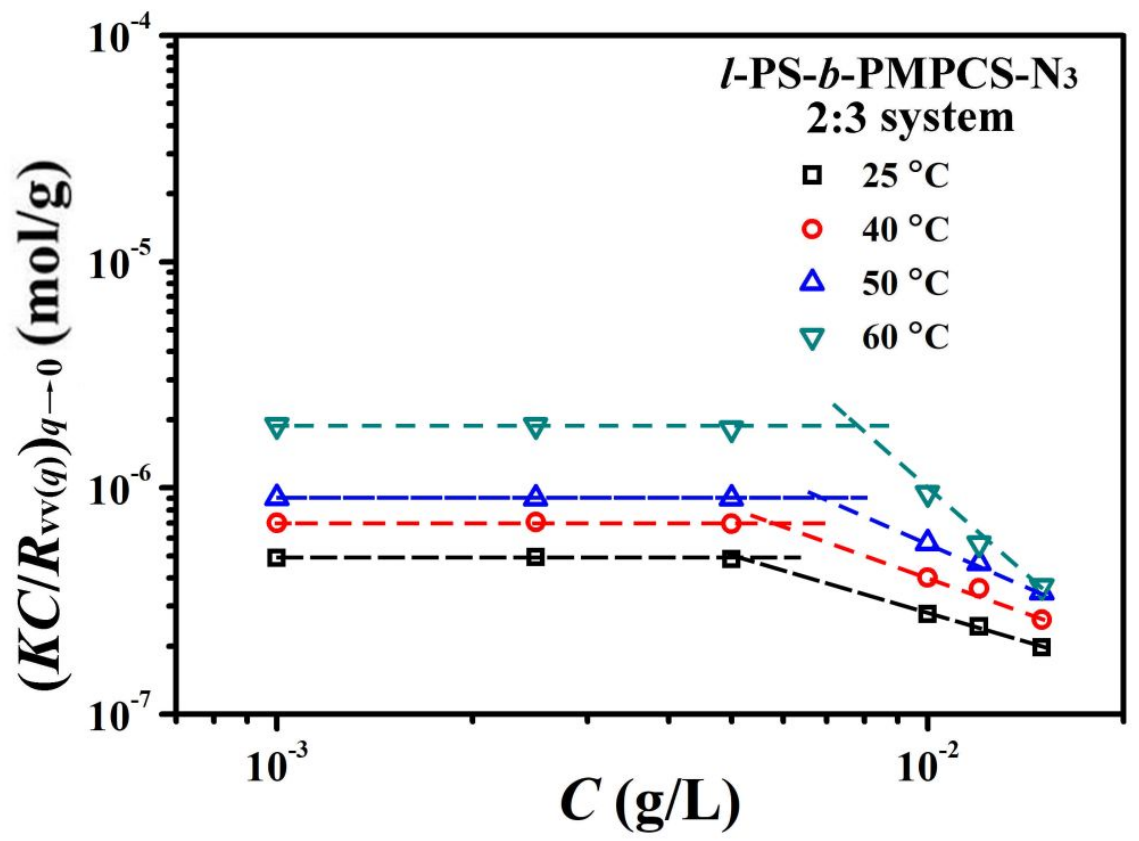

Figure S8. Concentration dependence of the reduced reciprocal scattered intensity $\left(K C / R_{\mathrm{vv}(q)}\right)_{q \rightarrow 0}$ of $l$-PS $90^{-} b$-PMPCS $5_{52}-\mathrm{N}_{3}$ in $2: 3\left(\mathrm{~V}_{\text {toluene }}: \mathrm{V}_{\text {cyclohexane }}\right)$ system at different temperatures $\left(25^{\circ} \mathrm{C}, 40\right.$ $\left.{ }^{\circ} \mathrm{C}, 50{ }^{\circ} \mathrm{C}, 60^{\circ} \mathrm{C}\right)$. 


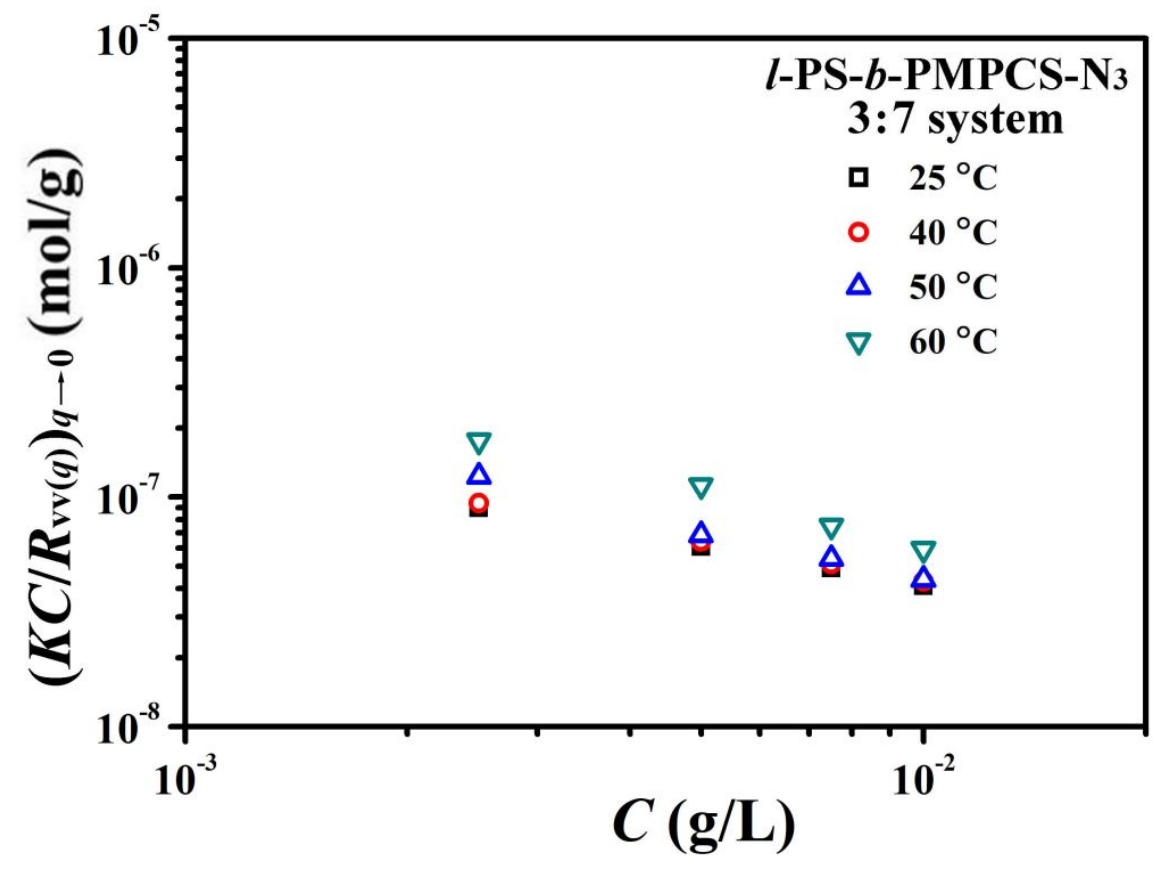

Figure S9. Concentration dependence of the reduced reciprocal scattered intensity $\left(K C / R_{\mathrm{vv}(q)}\right)_{q \rightarrow 0}$ of $l$-PS $90^{-} b$-PMPCS $5_{52}-\mathrm{N}_{3}$ in $3: 7\left(\mathrm{~V}_{\text {toluene }}: \mathrm{V}_{\text {cyclohexane }}\right)$ system at different temperatures $\left(25^{\circ} \mathrm{C}, 40\right.$ $\left.{ }^{\circ} \mathrm{C}, 50{ }^{\circ} \mathrm{C}, 60^{\circ} \mathrm{C}\right)$. 


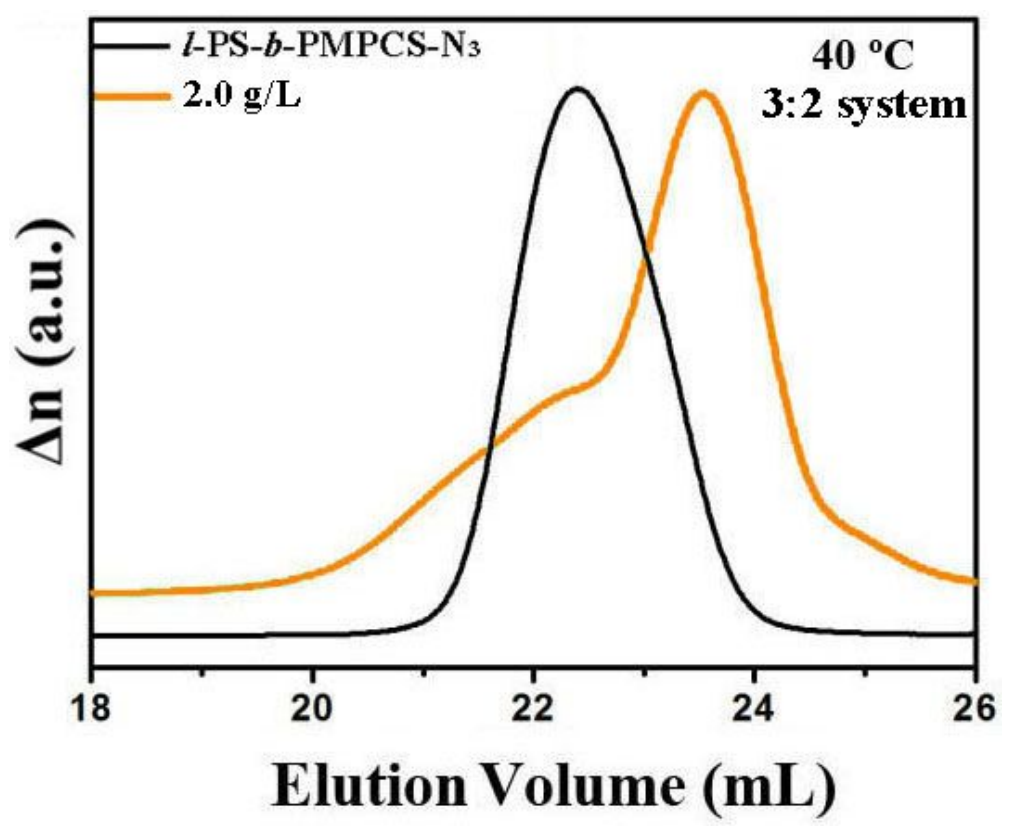

Figure S10. SEC curves of $l-\mathrm{PS}_{90}-b-\mathrm{PMPCS}_{52}-\mathrm{N}_{3}$ precursor, the cyclization product in toluene/cyclohexane (3:2 in volume) mixture solvent system with a concentration of $2.0 \mathrm{~g} / \mathrm{L}$ at $40{ }^{\circ} \mathrm{C}$. Eluent: DMF. 


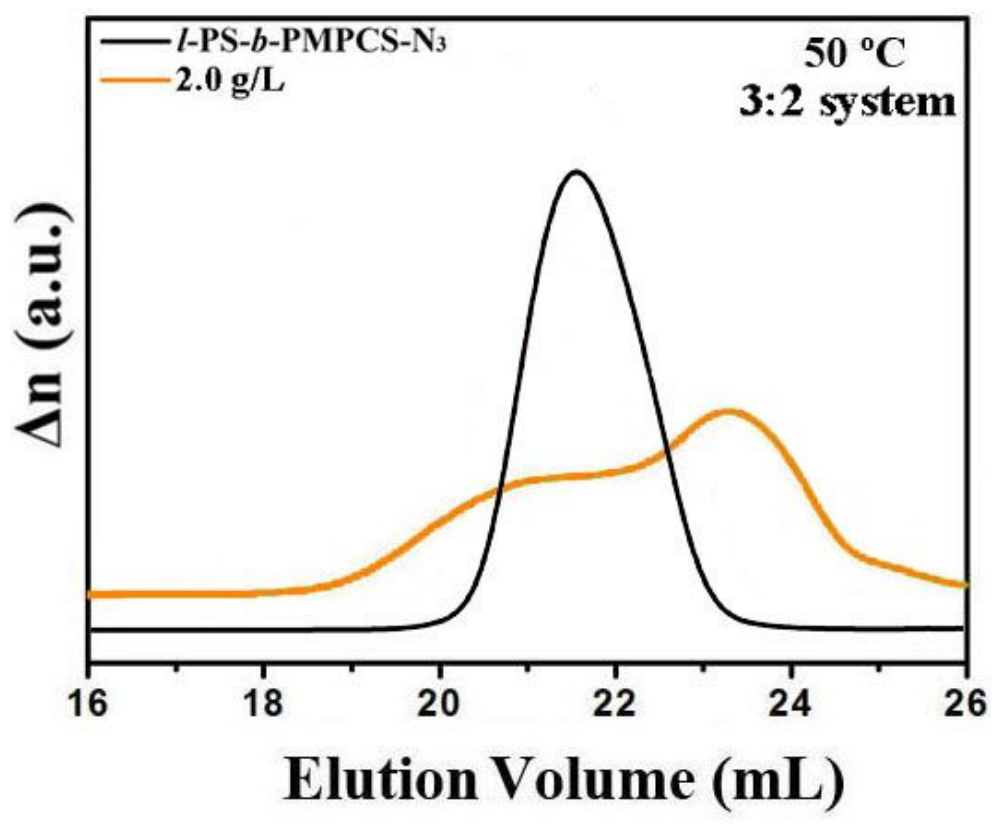

Figure S11. SEC curves of $l-\mathrm{PS}_{90}-b-\mathrm{PMPCS}_{52}-\mathrm{N}_{3}$ precursor, the cyclization products in toluene/cyclohexane (3:2 in volume) mixture solvent system with a concentration of $2.0 \mathrm{~g} / \mathrm{L}$ at $50{ }^{\circ} \mathrm{C}$. Eluent: DMF. 


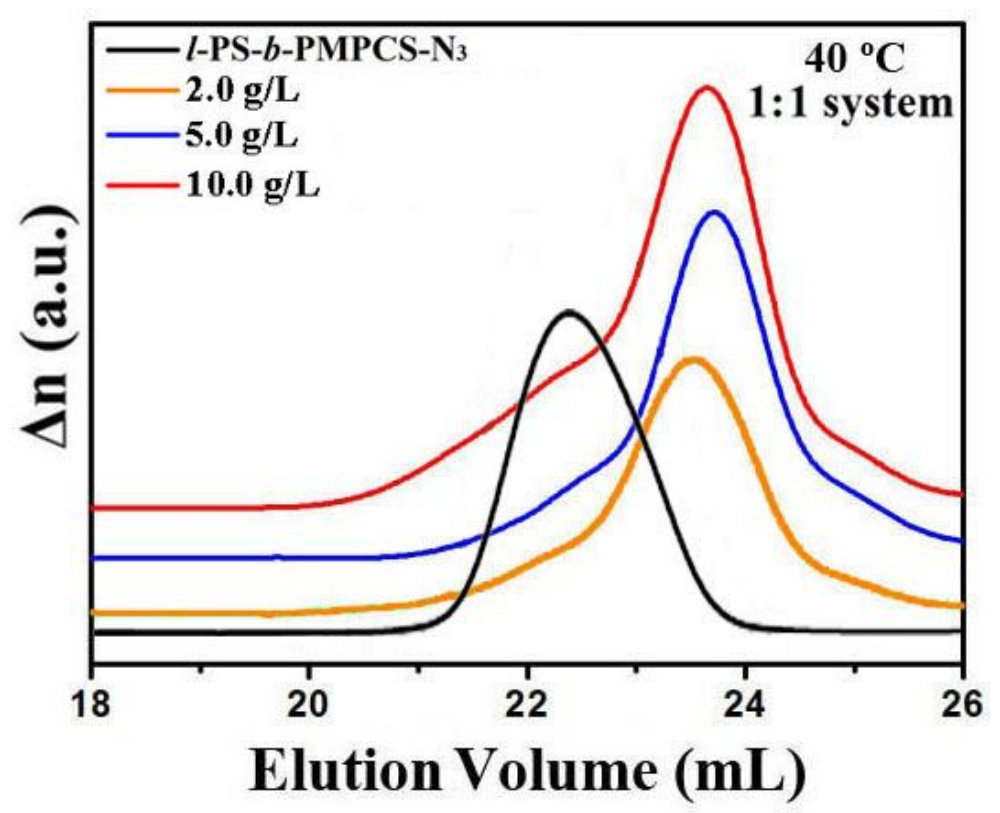

Figure S12. SEC curves of $l-\mathrm{PS}_{90}-b-\mathrm{PMPCS}_{52}-\mathrm{N}_{3}$ precursor, the cyclization products in toluene/cyclohexane (1:1 in volume) mixture solvent system with a concentration of 2.0, 5.0, $10.0 \mathrm{~g} / \mathrm{L}$ at $40^{\circ} \mathrm{C}$. Eluent: DMF. 


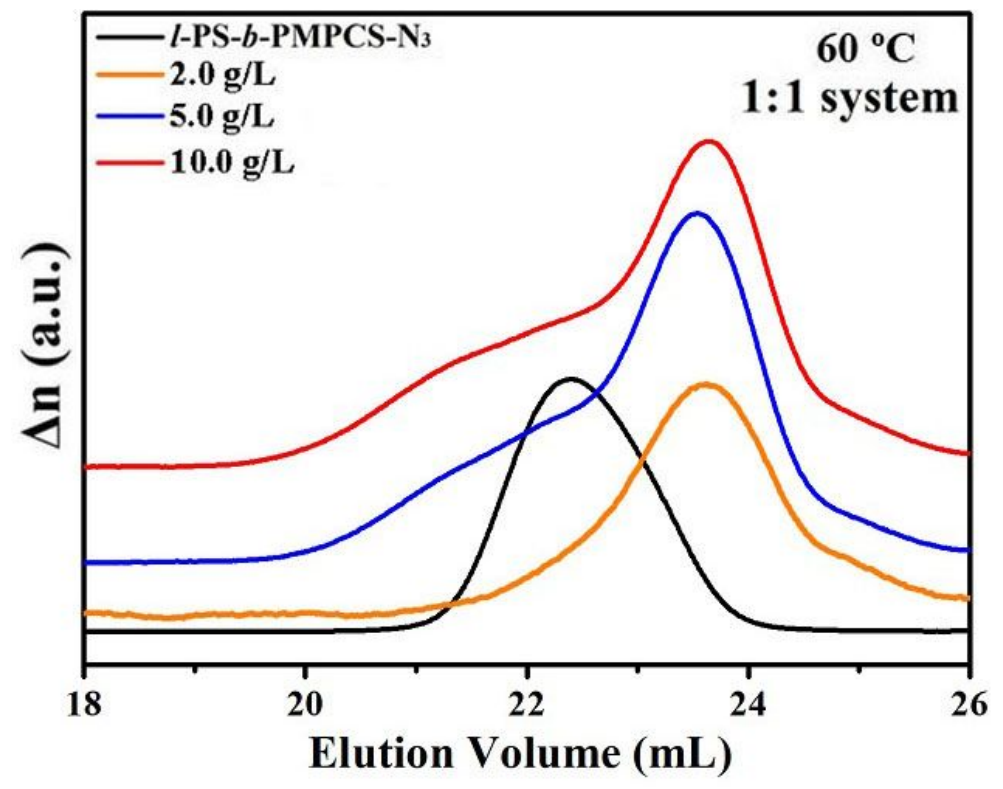

Figure S13. SEC curves of $l-\mathrm{PS}_{90}-b-\mathrm{PMPCS}_{52}-\mathrm{N}_{3}$ precursor, the cyclization products in toluene/cyclohexane (1:1 in volume) mixture solvent system with a concentration of 2.0, 5.0, $10.0 \mathrm{~g} / \mathrm{L}$ at $60^{\circ} \mathrm{C}$. Eluent: DMF. 


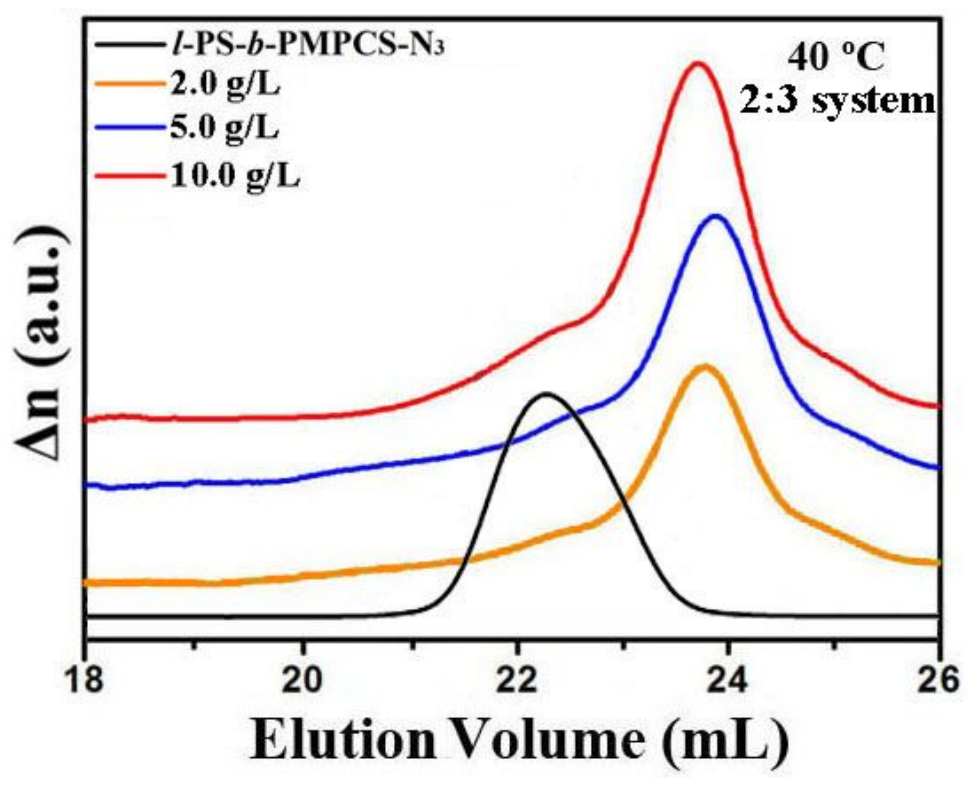

Figure S14. SEC curves of $l-\mathrm{PS}_{90}-b-\mathrm{PMPCS}_{52}-\mathrm{N}_{3}$ precursor, the cyclization products in toluene/cyclohexane (2:3 in volume) mixture solvent system with a concentration of 2.0, 5.0, $10.0 \mathrm{~g} / \mathrm{L}$ at $40{ }^{\circ} \mathrm{C}$. Eluent: DMF. 


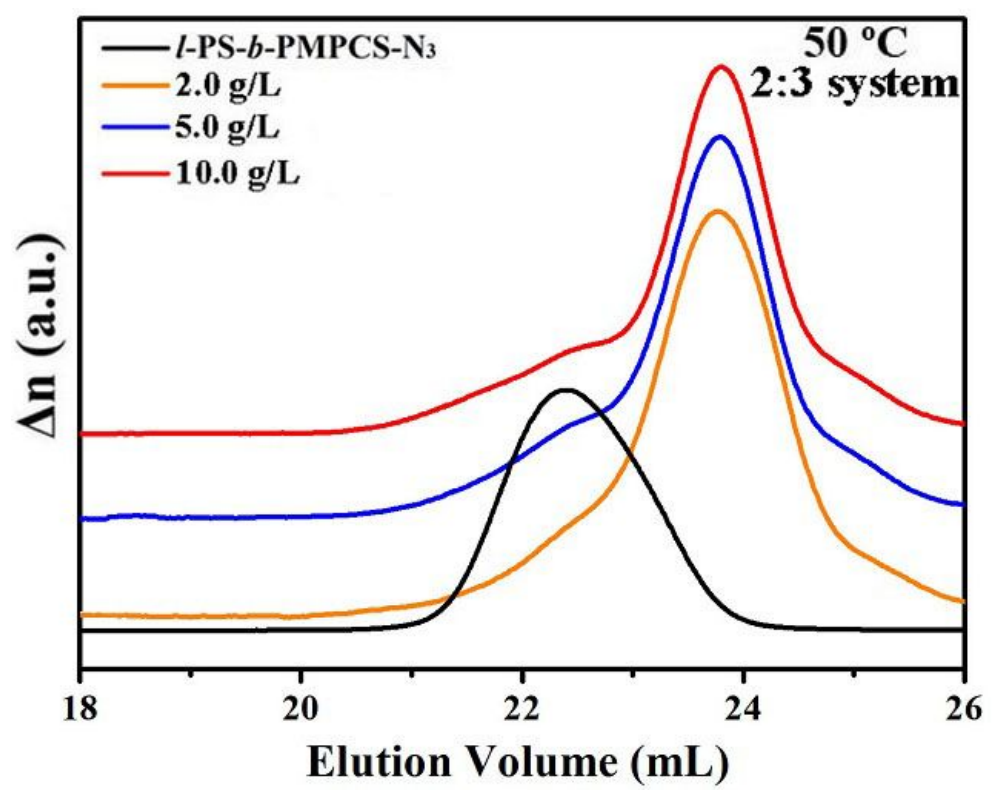

Figure S15. SEC curves of $l-\mathrm{PS}_{90}-b-\mathrm{PMPCS}_{52}-\mathrm{N}_{3}$ precursor, the cyclization products in toluene/cyclohexane (2:3 in volume) mixture solvent system with a concentration of 2.0, 5.0, $10.0 \mathrm{~g} / \mathrm{L}$ at $50^{\circ} \mathrm{C}$. Eluent: DMF. 


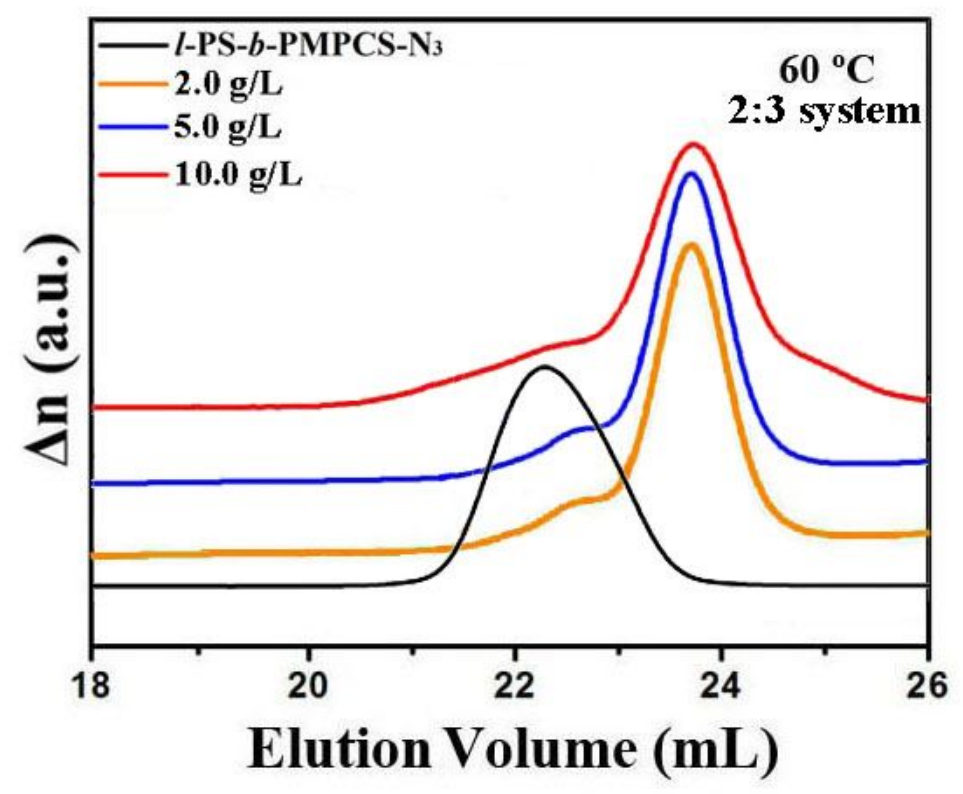

Figure S16. SEC curves of $l-\mathrm{PS}_{90}-b-\mathrm{PMPCS}_{52}-\mathrm{N}_{3}$ precursor, the cyclization products in toluene/cyclohexane (2:3 in volume) mixture solvent system with a concentration of 2.0, 5.0, $10.0 \mathrm{~g} / \mathrm{L}$ at $60^{\circ} \mathrm{C}$. Eluent: DMF. 


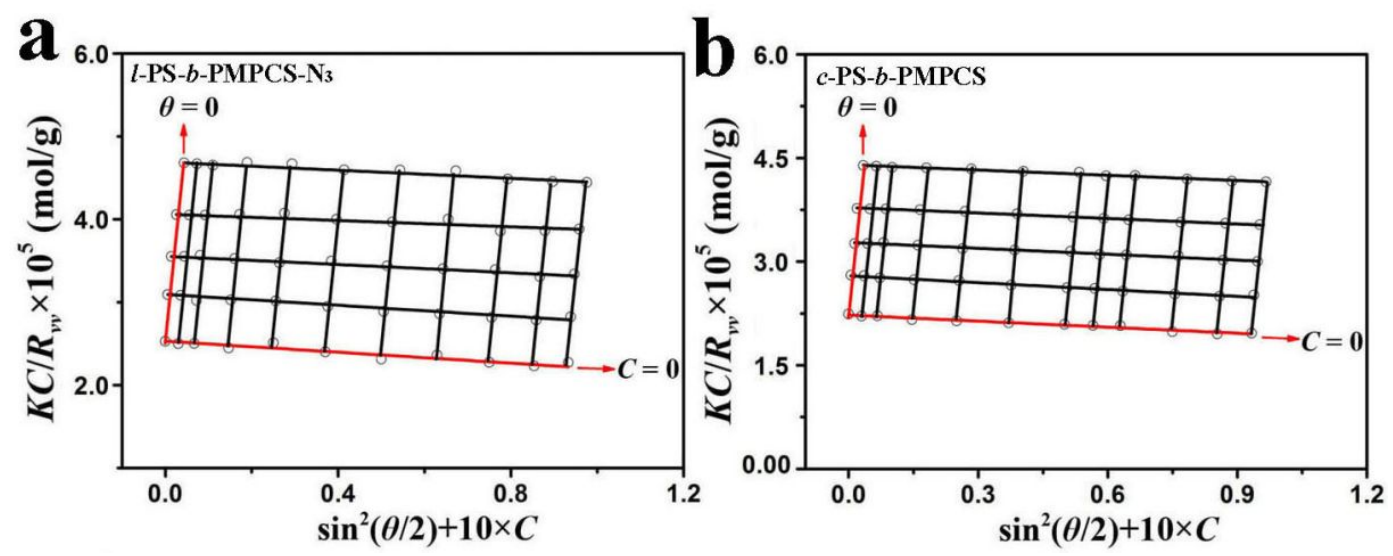

Figure S17. Zimm plot of $l-\mathrm{PS}_{90}-b-\mathrm{PMPCS}_{52}-\mathrm{N}_{3}$ (a) and $c-\mathrm{PS}_{90}-b-\mathrm{PMPCS}_{52}$ (b) in toluene at $25^{\circ} \mathrm{C}$. 


\section{$\mathrm{CD}_{2} \mathrm{Cl}_{2}$}
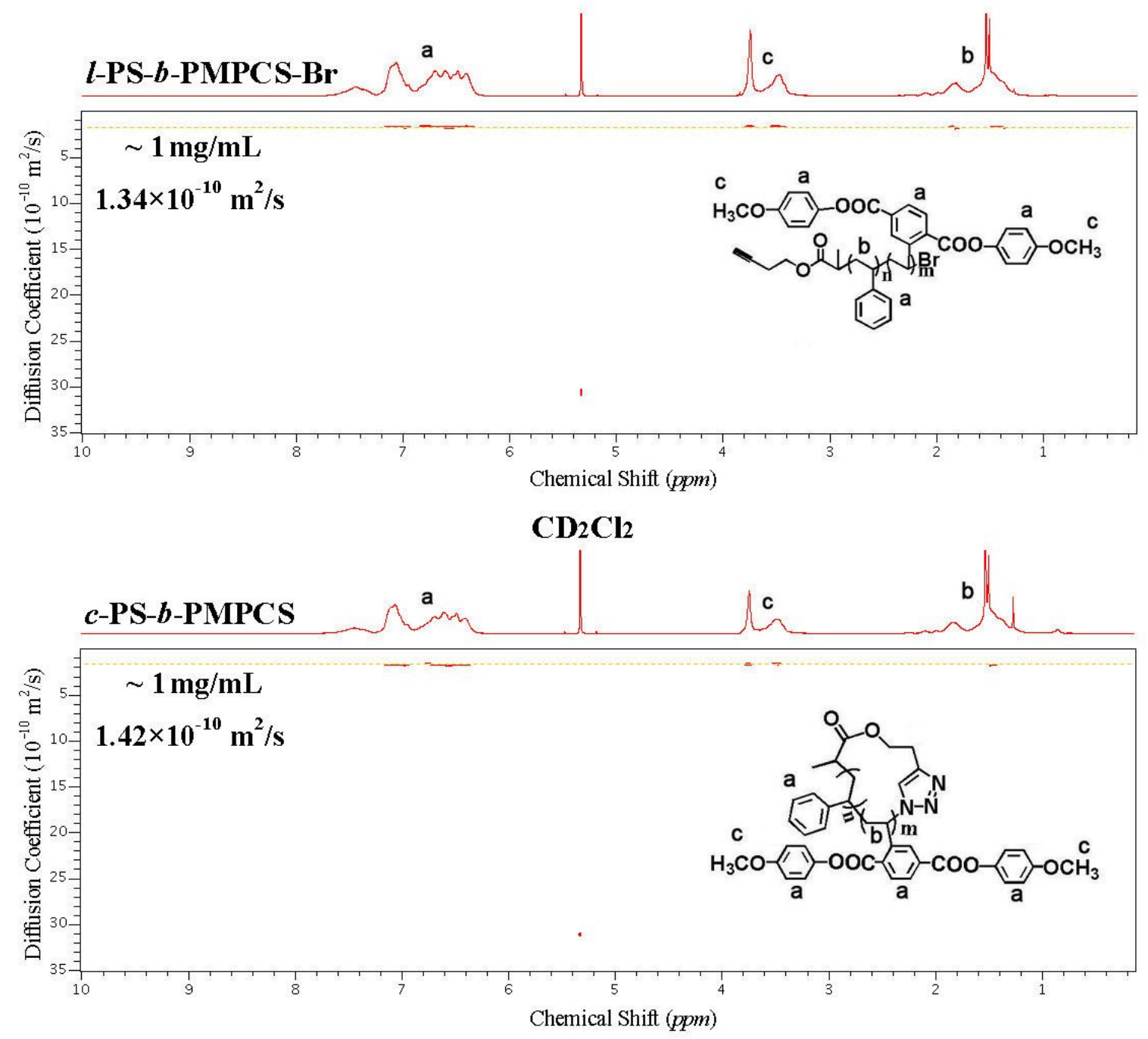

Figure S18. DOSY spectra of $l-\mathrm{PS}_{90}-b-\mathrm{PMPCS}_{52}-\mathrm{Br}$ and $c-\mathrm{PS}_{90}-b-\mathrm{PMPCS}_{52}$ in $\mathrm{CD}_{2} \mathrm{Cl}_{2}$ at $25^{\circ} \mathrm{C}$. 


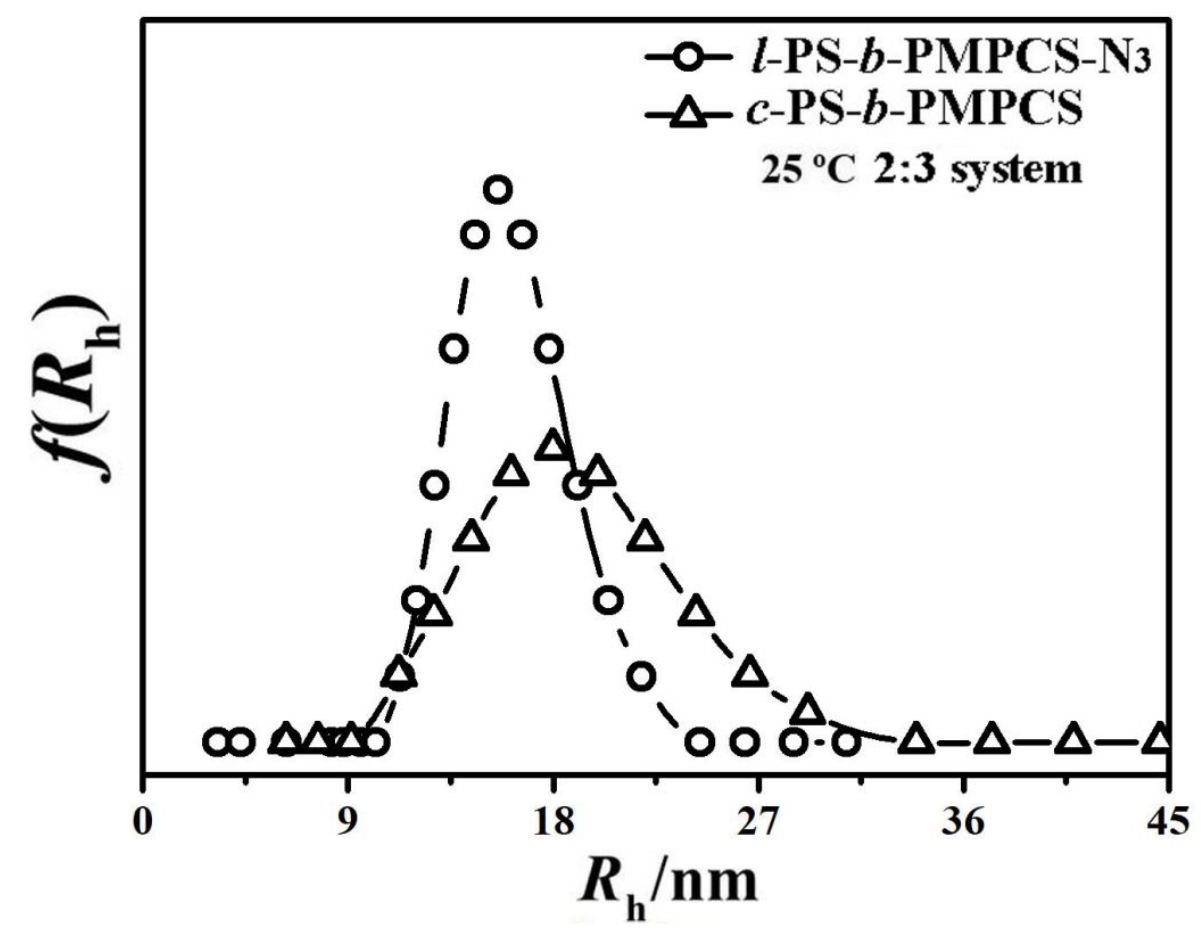

Figure S19. The hydrodynamic radius distribution $f\left(R_{\mathrm{h}}\right)$ of self-assembled micelles from linear and cyclic rod-coil diblock copolymer at $0.4 \mathrm{~g} / \mathrm{L}$ in $2: 3$ ( $\mathrm{V}_{\text {toluene }}: \mathrm{V}_{\text {cyclohexane }}$ ) system at $25^{\circ} \mathrm{C}$. 


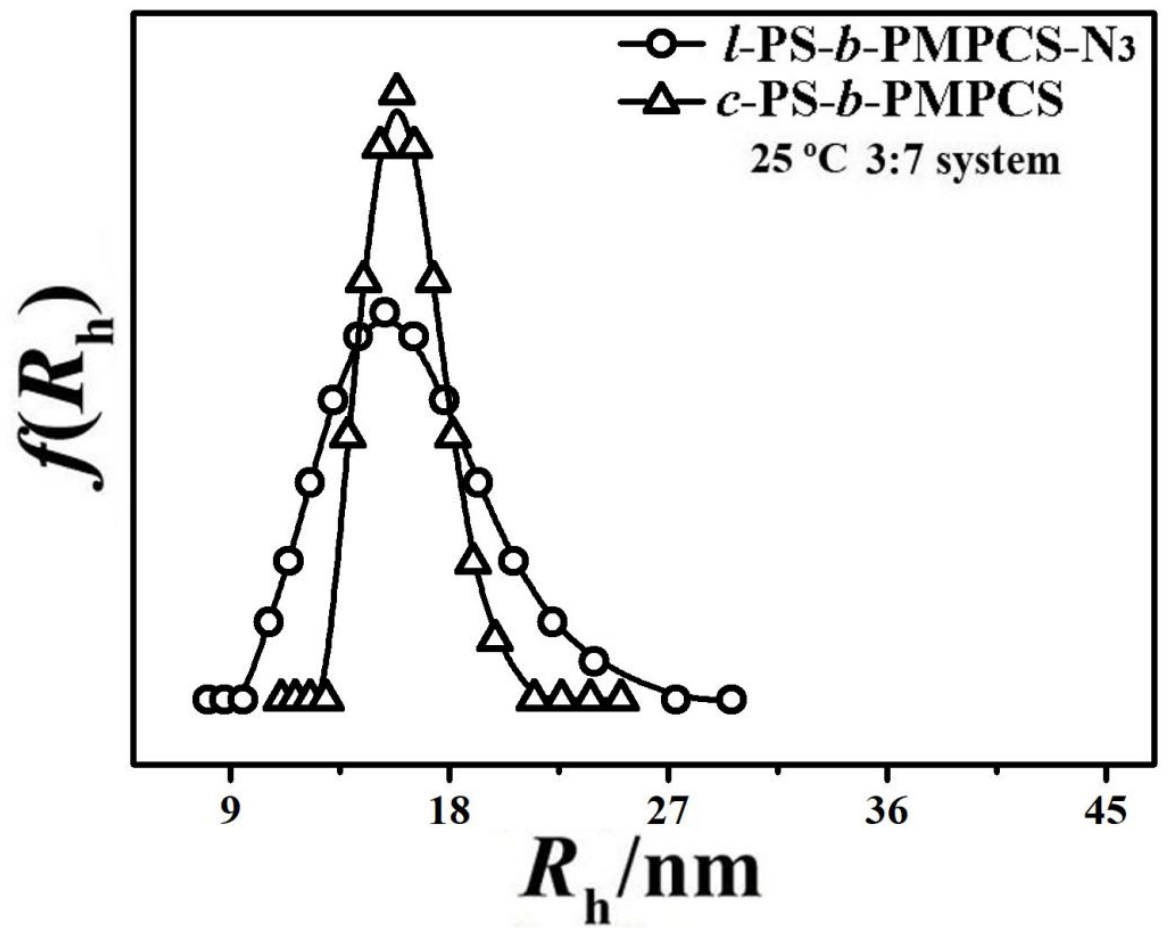

Figure S20. The hydrodynamic radius distribution $f\left(R_{\mathrm{h}}\right)$ of self-assembled micelles from linear and cyclic rod-coil diblock copolymer at $0.4 \mathrm{~g} / \mathrm{L}$ in $3: 7\left(\mathrm{~V}_{\text {toluene }}: \mathrm{V}_{\text {cyclohexane }}\right)$ system at $25^{\circ} \mathrm{C}$. 


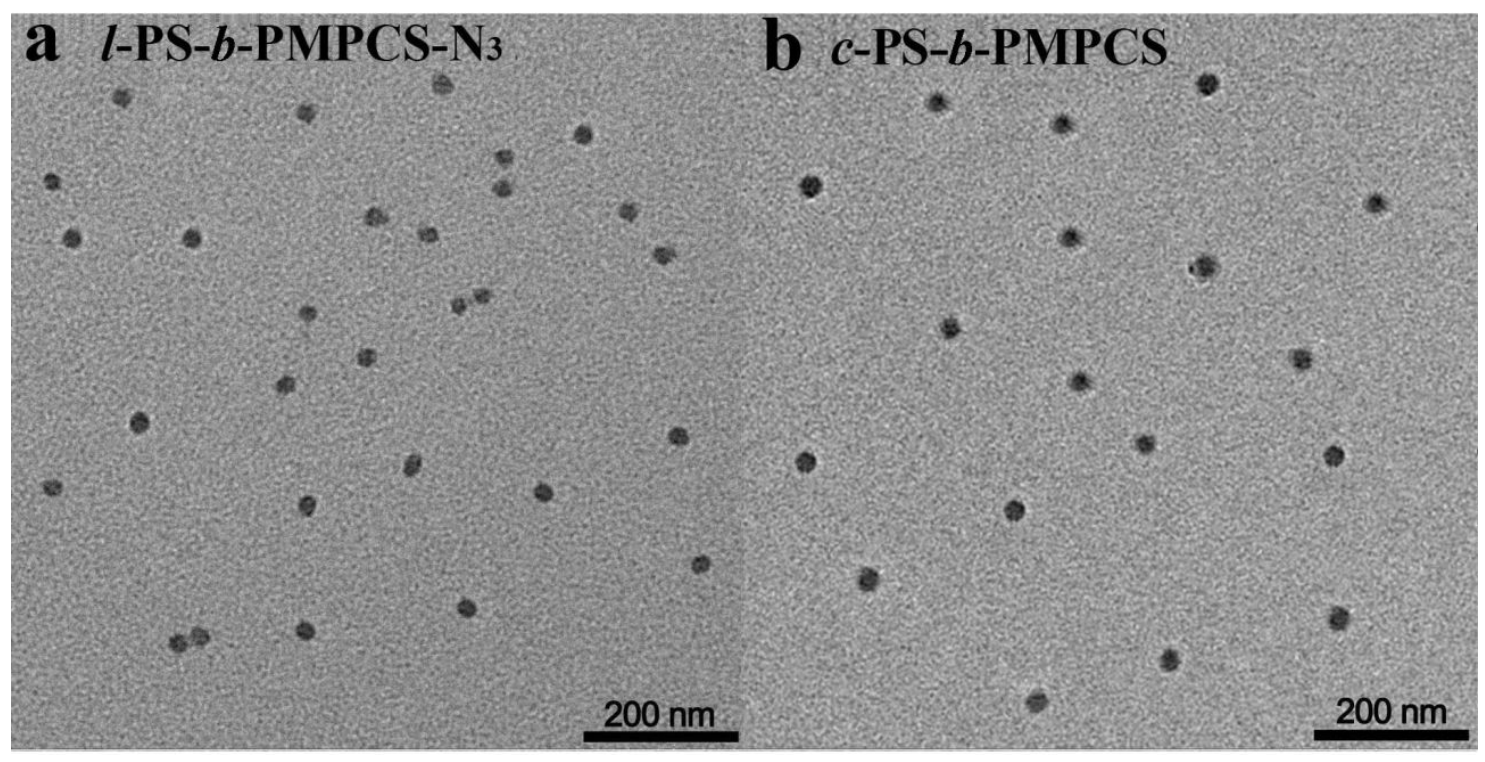

Figure S21. TEM image of self-assembled micelles from linear and cyclic diblock copolymer in 3:7 ( $\left.\mathrm{V}_{\text {toluene }}: \mathrm{V}_{\text {cyclohexane }}\right)$ system at $0.2 \mathrm{~g} / \mathrm{L}$. 


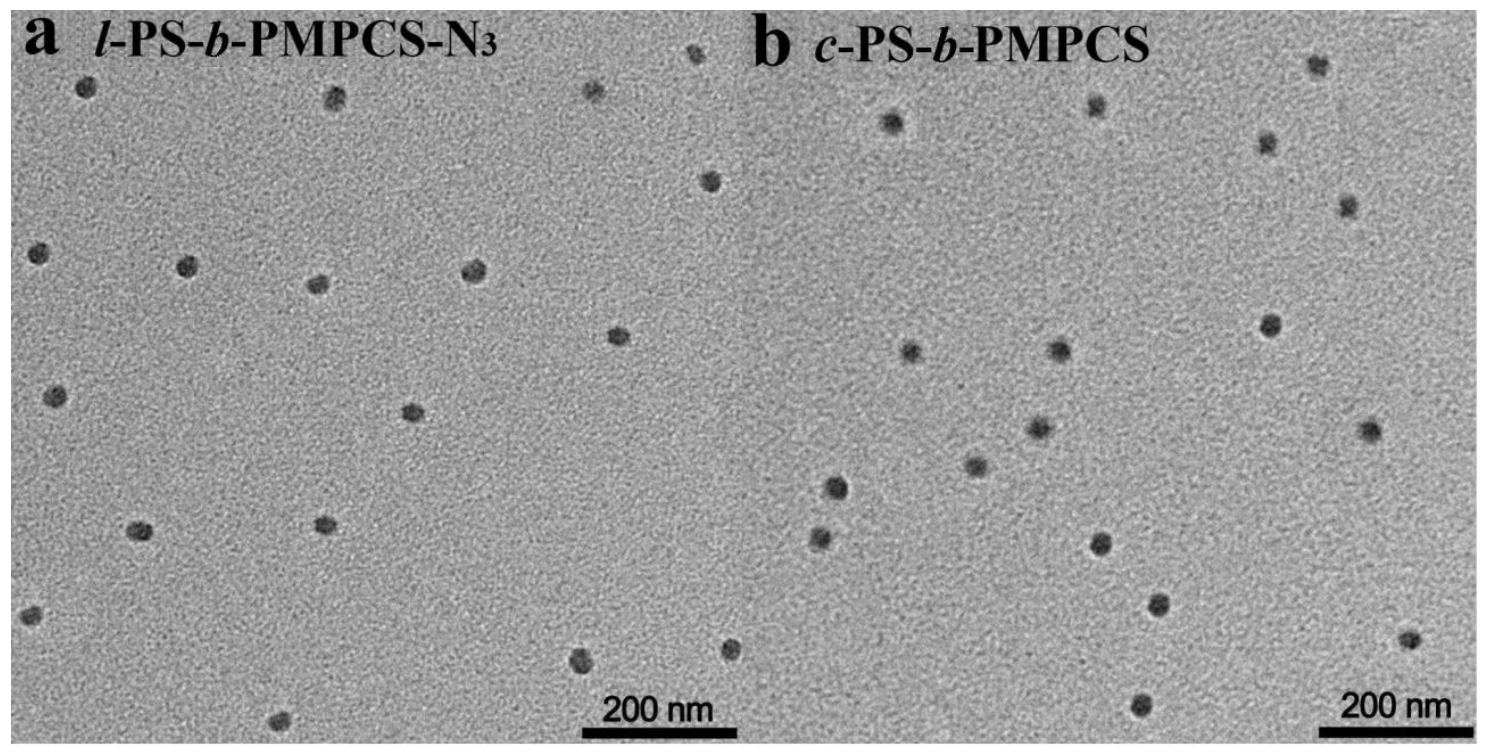

Figure S22. TEM image of self-assembled micelles from linear and cyclic rod-coil diblock copolymer in 2:3 ( $\left.\mathrm{V}_{\text {toluene }}: \mathrm{V}_{\text {cyclohexane }}\right)$ system at $0.2 \mathrm{~g} / \mathrm{L}$. 

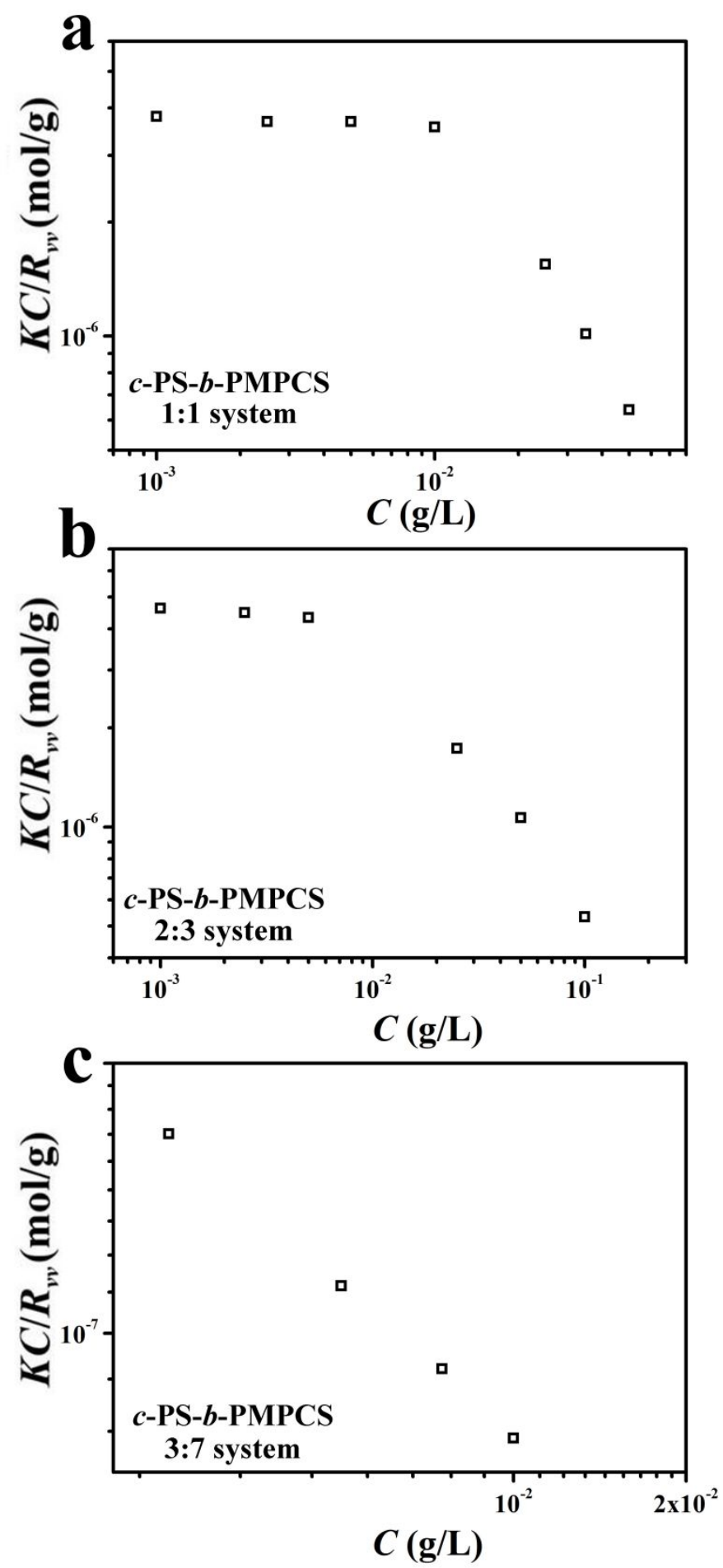

Figure S23. Concentration dependence of the reduced reciprocal scattered intensity $\left.\left(K C / R_{\mathrm{vv}(q)}\right)_{q \rightarrow 0}\right)$ of $c-\mathrm{PS}_{90}-b-\mathrm{PMPCS}_{52}$ at $25{ }^{\circ} \mathrm{C}$ with $1: 1 \quad\left(\mathrm{~V}_{\text {toluene: }}: \mathrm{V}_{\text {cyclohexane }}\right)$ system (a), 2:3 $\left(\mathrm{V}_{\text {toluene }}: \mathrm{V}_{\text {cyclohexane }}\right)$ system (b) and 3:7 ( $\left.\mathrm{V}_{\text {toluene }}: \mathrm{V}_{\text {cyclohexane }}\right)$ system (c). 

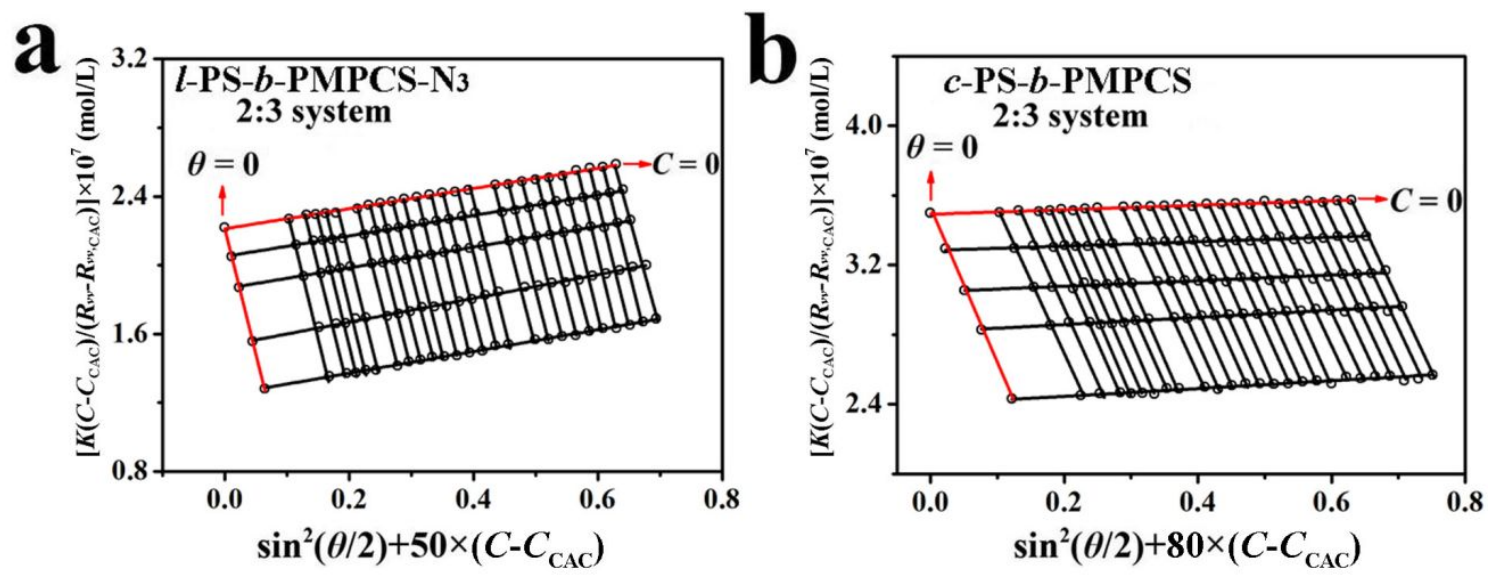

Figure S24. Zimm plots of self-assembled micelles from $l$-PS $90-b-\mathrm{PMPCS}_{52}-\mathrm{N}_{3}$ (a) and $c-\mathrm{PS}_{90}-b$ $\mathrm{PMPCS}_{52}$ (b) rod-coil diblock copolymers in 2:3 ( $\left.\mathrm{V}_{\text {toluene }}: \mathrm{V}_{\text {cyclohexane }}\right)$ system at $25^{\circ} \mathrm{C}$. 

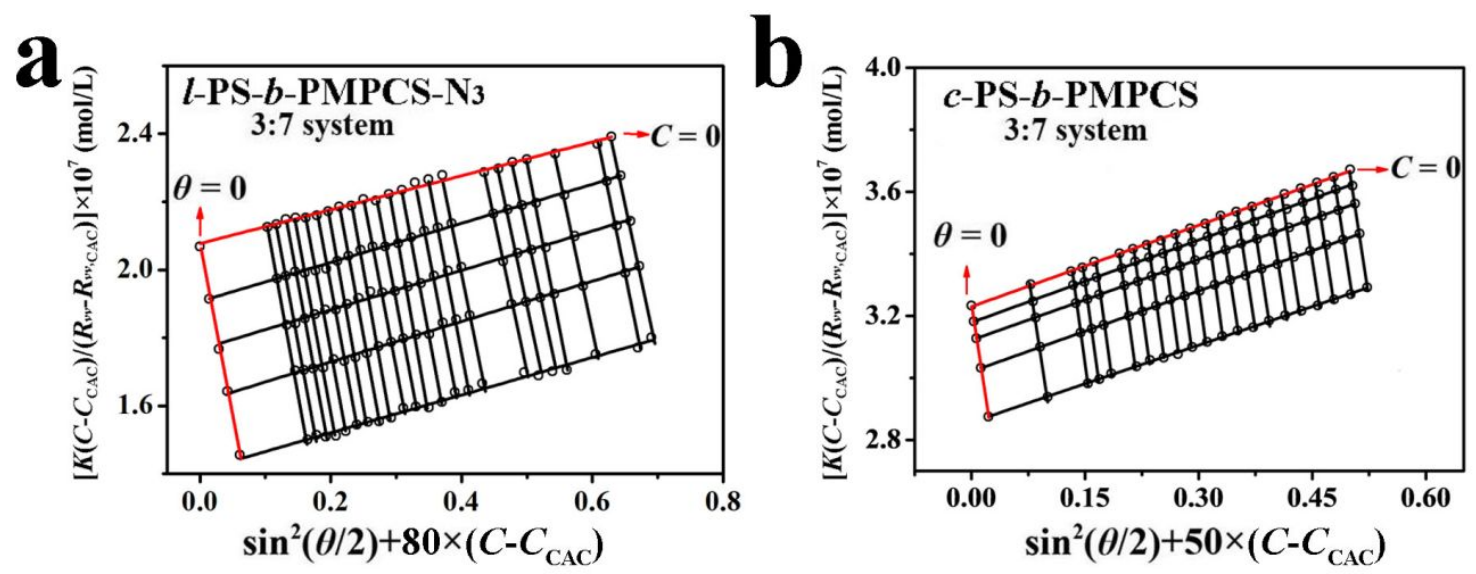

Figure S25. Zimm plots of self-assembled micelles from $l$-PS $90-b-\mathrm{PMPCS}_{52}-\mathrm{N}_{3}$ (a) and $c-\mathrm{PS}_{90}-b$ $\mathrm{PMPCS}_{52}$ (b) rod-coil diblock copolymers in $3: 7\left(\mathrm{~V}_{\text {toluene }}: \mathrm{V}_{\text {cyclohexane }}\right)$ system at $25^{\circ} \mathrm{C}$. 


\section{References}

1. D. Zhang, Y. X. Liu, X. H. Wan, Q. F. Zhou, Macromolecules 1999, 32, 5183-5185.

2. A. Touris, N. Hadjichristidis, Macromolecules 2011, 44, 1969-1976.

3. Y. Tu, X. Wan, H. Zhang, X. Fan, X. Chen, Q. Zhou, K. Chau, Macromolecules 2003, 36, 6565-6569.

4. C. Wu, K. Q. Xia, Rev. Sci. Instrum. 1994, 65, 587-590.

5. P. Debye, J. Colloid Sci. 1948, 3, 407-409.

6. Y. Tu, X. Wan, D. Zhang, Q. Zhou, C. Wu, J. Am. Chem. Soc. 2000, 122, 10201-10205. 